\title{
Considering Cultural Variables in the Instructional Design Process: A Knowledge- Based Advisor System
}

Isabelle Savard, Jacqueline Bourdeau, Gilbert Paquette

Isabelle.savard@teluq.ca

\begin{abstract}
This article presents research works in which a cultural adaptation method and a knowledge-based advisor to help instructional designers in considering cultural variables during the instructional design process have been developed. To do so, a conceptual model of Culture was elaborated, cultural variables were identified and knowledge regarding these variables was modeled via an ontology that served to create the "Cultural Diversity" knowledge base integrating knowledge regarding five cultures. The advisor tool uses this knowledge to advise instructional designers on how to adapt a pedagogical scenario to a culture other than their own or for learners with a culture that is different from the one for which a pedagogical scenario was originally designed. The methodology used is Design-Based Research (DBR) and contains five iterations.
\end{abstract}

Keywords: Instructional Design, Cultural Variables, Knowledge-Based Advisor System, Ontology, Design-Based Research

\section{1- Introduction}

The internationalization of education has created new contexts that have given rise to new challenges in education. E-Learning continues to gain in popularity. This may be due to the strong desire on the part of many universities to reach an international clientele, to the growing need for continuing professional education and to the exponential increase in the number of learners with Internet access. Even while remaining in their countries, students no longer hesitate to study "abroad". Professors also have more opportunities to give their courses to learners from a culture other than their own or than that of learners for whom their courses were originally designed, via distance education or by teaching abroad.

Some of the new challenges relate to the fact that the pedagogical resources used are not always adapted to the cultural realities of the learners for whom they are intended. Also, as pointed out by Rogers, Graham and Mayes (2007), 
professors are not always aware or even informed of the existence of cultural variables in educational practices. The result is that these variables are too often overlooked, and this may lead to difficulties in adaptation for both learner and teacher. We believe that such difficulties can have a significant impact on competency development or on the achievement of other learning goals. We also believe that it is important to consider cultural variables in the instructional design process, but as Blanchard and Mizoguchi (2014), Edmundson (2007), Goodyear (2001), Man (2004) and Young (2008) have all pointed out, too few tools and guidelines exist to assist instructional designers in this task.

We believe that access to formally represented knowledge can facilitate this task by making explicit what is implicit (and in all likelihood different from one culture to another).

Blanchard and Mizoguchi (2014) used a declarative approach to model knowledge about the cultural domain. As they explain, their goal is to "concentrate and structure in one place the many scientific-grade notions needed to get a coherent view of the cultural domain..." Their work can be used to situate or anchor cultural efforts of adaptation in a theory and to understand the cultural domain more thoroughly, but it does not serve the adaptation process itself.

This paper presents the design and functional testing of a knowledge-based advisor system that guides the instructional designer in his or her cultural adaptation tasks. The methodology used is Design-Based Research (DBR) (Bell, 2004), with five iterations. DBR is a systematic yet flexible methodology with the goal of improving educational practices through iterative analyses, design, development and implementation in natural contexts in order to establish theoretical principles and proposals (Wang \& Hannafin, 2005) According to Reeves (2000), the goal of this type of developmental research is to solve existing and real problems, while constructing design principles that could inform future decision making. During the five iterations in the DBR process, procedural knowledge about culture was first modeled to illustrate how culture can affect our day-to-day lives, but particularly teaching and learning (see The Conceptual Model of Culture in Section 3 below). Subsequently, declarative knowledge about cultural variables in the instructional design process and their characterization in specific cultures (see 
4- Cultural Variables and 5- Cultural Variables Ontology and Cultural Diversity Knowledge Base) were modeled. Finally, an executable cultural adaptation method was modeled and a prototype of an advisor system developed (see Section 5). This prototype uses formally represented knowledge to advise instructional designers on how to adapt a pedagogical scenario (for a lesson, a course or even a curriculum) to a culture other than their own or than that of learners for whom their pedagogical scenarios were originally designed. The mix of both procedural and declarative knowledge allows for offering tools that facilitate the cultural adaptation process. This work provides answers to the following questions: How can culture affect learning and teaching? How can the notion of culture and its functions be defined? What varies in pedagogical scenarios from one culture to another? How can the instructional designer adapt to a new culture?

\section{2- Methodology}

\subsection{Methodological Framework}

The research methodology used is a combination of Design-Based Research (DBR) and the Unified Process (UP) (Larman, 2004) used for the development of the advisor system prototype.

Three principal characteristics of DBR stand out, i.e., its dual purpose, which consists in understanding the phenomena studied and adjusting the design (interventionist); its flexibility, which makes it possible to modify the protocol and the design in the process; and its openness, on the basis of which a DBR protocol may combine quantitative and qualitative methods and techniques. Herrington, McKenney, Reeves and Oliver (2007) drew attention to the multiple products of DBR, i.e., scientific outputs in the form of design principles, practical outputs in the form of solutions (artifacts, products) derived from a design process, and societal outputs through the professional development of practitioners. Indeed, DBR makes it possible to conduct research based, to a greater extent, on the concerns and problems of practitioners and to develop solutions in collaboration with them. It is a methodological framework that is anchored in and thus facilitates a practical approach to the advancement of knowledge in terms of design principles. 
Figure 1 is a free adaptation of Reeves (2006). It presents the five steps of DBR: analyzing practical problems with collaboration between practitioners and researchers; developing theories, solutions and technological innovations; conducting iterative cycles of testing and refining theories and solutions in practice; reflecting on producing theories and design principles and emphasizing solution implementation; and, finally, refining theories, problems, solutions and design principles. Figure 1 is said to be adapted, since it is a free translation by the authors in which references were added in respect of the development, production and refinement of theories - concepts that are present elsewhere in the literature (Bell, 2004; Brown, 1992; Collective, 2003; Collins, 1992; DiSessa \& Cobb, 2004; Mor, 2011; Wang \& Hannafin, 2005), and in which a loop required for the development of our solution was added between steps 2 and 3 .

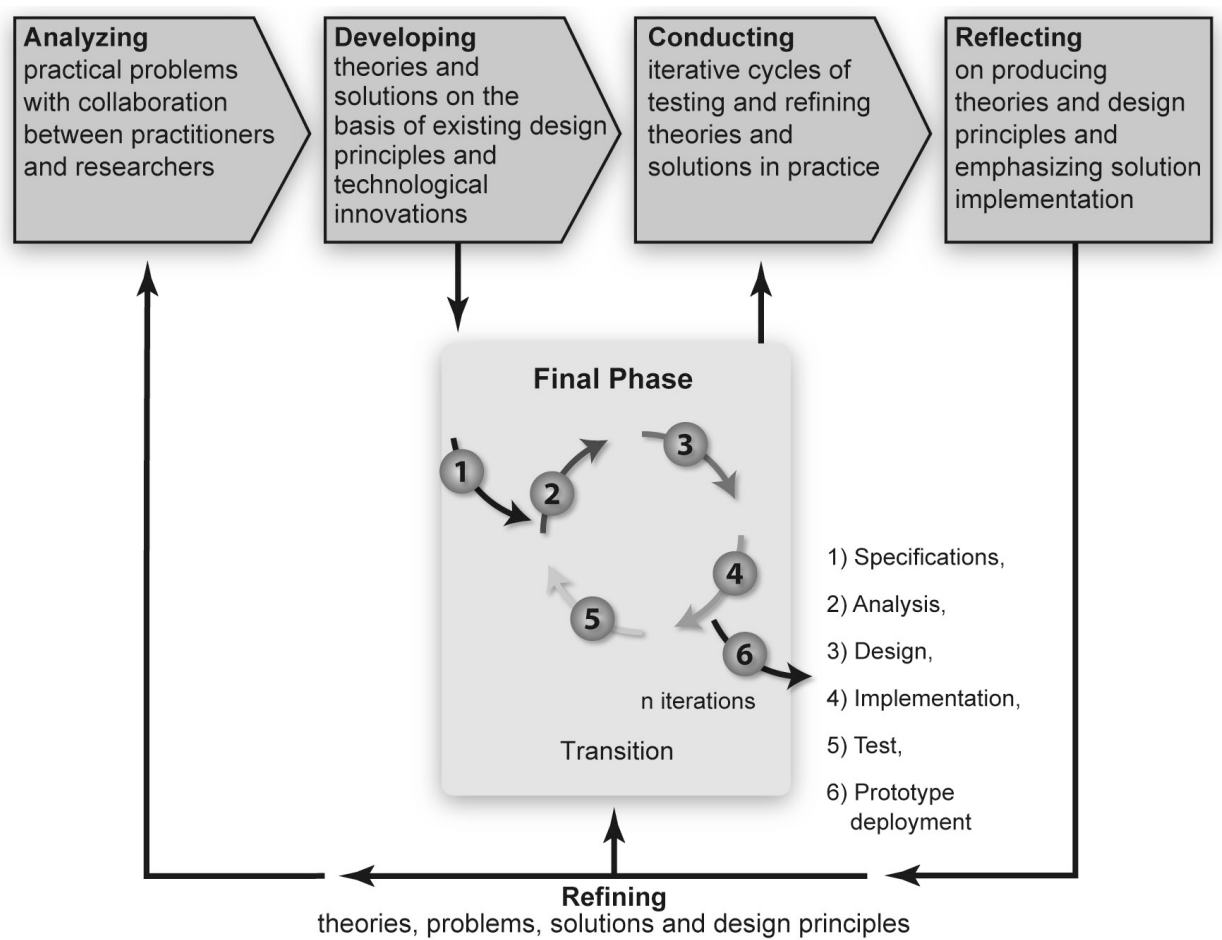

Figure 1 Complementarity between the Steps of Design-Based Research (adapted from Reeves (2006)) and Those of the Unified Process (Larman, 2004)

For the development of the system prototype, the Unified Process (UP) (Larman, 2004) was used as a basis for the work, since it encompasses recognized and exemplary practices. The Unified Process is also flexible and open, and it 
encourages the inclusion of practices derived from other iterative methods (Larman, 2004), such as, in this case, those from Design-Based Research.

The Unified Process is driven by use cases; it is iterative and incremental. An iteration is characterized by the succession of the steps in an activity. Each iteration includes requirements, as well as analysis, design, implementation and testing activities. An increment constitutes an advance in the developmental stages of the prototype. The Unified Process consists of a cycle within which the iterations are grouped together by phases. These phases are either initial (inception), intermediate (elaboration, construction), or final (transition to the user). The number of iterations in each of the phases is variable and unlimited $a$ priori.

In the initial phase, more time is normally spent on analysis activities than on tests. The inverse is also true: in the transition phase, more time should be spent on tests than on the analysis. The objectives of each of the phases are reached through the execution of one or several iterations in the phase. Each of the phases of the cycle is completed by a significant event (often a new version of the prototype), which makes it possible to determine whether the project has achieved the objectives of the phase. In this case, the UP phases for the advisor system's development were conducted in complementarity with the various steps and iterations of DBR, which was the main methodology.

Certain activities, which are set out in the Unified Process, were completed within the framework of DBR and were not repeated. For example, the requirements, analysis, design, and ontology and method testing completed in the framework of DBR were reused directly as inputs in the development of the advisor system prototype (following the Unified Process). DBR provided many inputs, in particular for the analysis and design steps, since it is in this framework that the tools and principles on which the advisor system is based were developed. More specifically, these tools are the cultural variables ontology, the "Cultural Diversity" knowledge base and the method to treat cultural variables (see Section 5 for a more detailed description of the tools).

In the same way, DBR suggests an incremental and iterative approach to functioning. During the initial iterations, more time was spent on analysis, 
whereas the final iterations allowed for more time to be spent on reflecting on, developing and refining solutions and design principles. Figure 2 presents an overview of the methodology and illustrates the processes (UP and DBR), the main products of each of the five iterations and the validation techniques used.

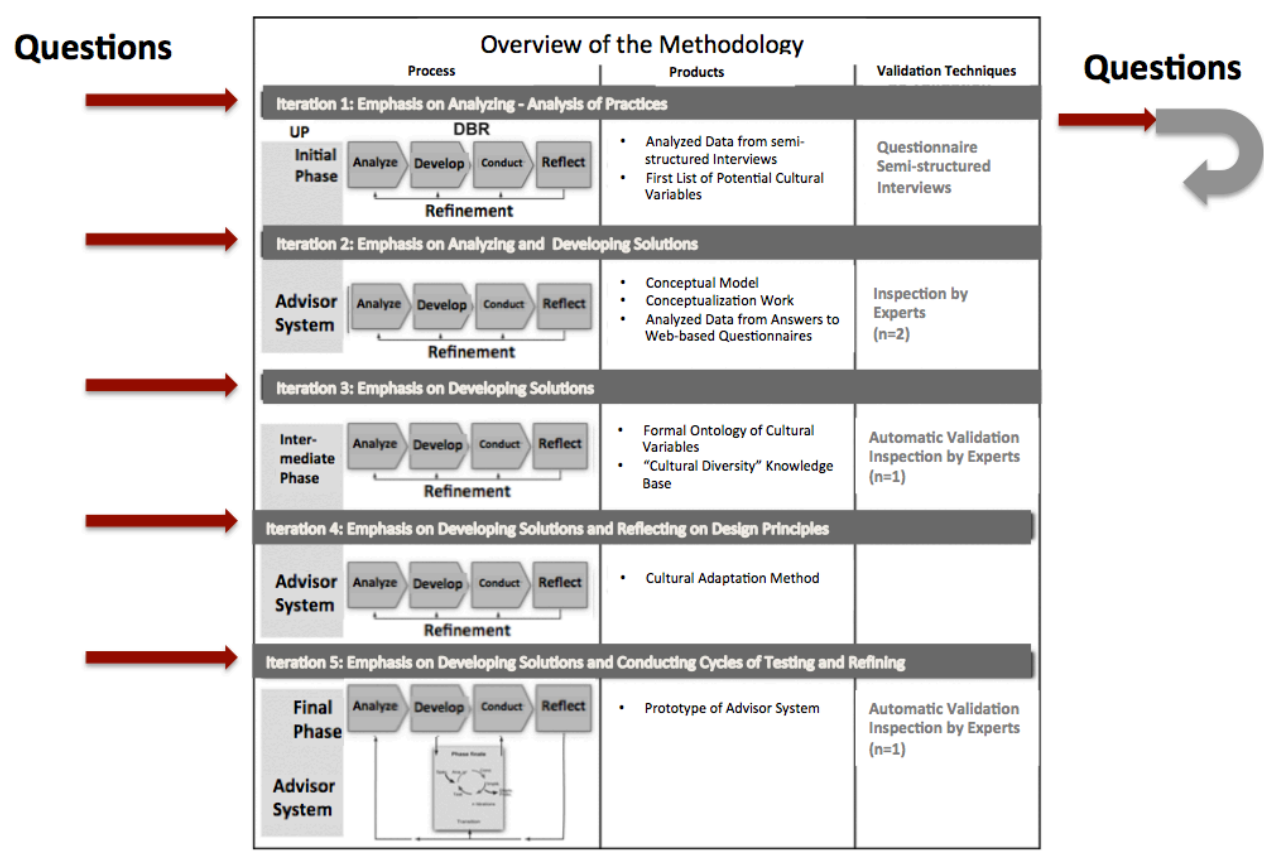

Figure 2 Overview of the Methodology

At the start of each of the iterations of the DBR, several questions were considered. The reflections in terms of the iterations led the researchers to refine the problem and to consider additional questions. The latter served systematically as input for the subsequent iteration. Table 1 below presents the list of input questions per iteration.

Table 1 List of Input Questions per Iteration

\begin{tabular}{|l|l|}
\hline Iteration & Questions \\
\hline 1 & Is cultural adaptation perceived as a need in the field? \\
\hline 2 & $\begin{array}{l}\text { How can the notion of culture and its functions be defined? } \\
\text { How can culture influence learning and teaching? }\end{array}$ \\
\hline 3 & What varies in a pedagogical scenario from one culture to another? \\
\hline 4 & $\begin{array}{l}\text { How can the instructional designer adapt to a new culture? } \\
\text { What should a systematic method for the treatment of cultural variables include? } \\
\text { How can such a method remain generic enough (yet effective) to be integrated into any } \\
\text { instructional design method? }\end{array}$ \\
\hline 5 & $\begin{array}{l}\text { Where should the advice be integrated and how do we ensure that all the advice does not } \\
\text { appear to all the users but only to those who need it? } \\
\text { How do we ensure that the designer maintains design authority over his or her scenario and } \\
\text { that the decision to take the advice or not always remains with him or her? }\end{array}$ \\
\hline
\end{tabular}




\subsection{Data Collection Techniques and Instruments}

The techniques and instruments used to collect data included observations and qualitative classification, a semi-structured interview and a questionnaire.

For iteration 1, a semi-structured interview was chosen because, as Kember, $\mathrm{Ma}$ and McNaught (2006, p. 11) point out, it allows key elements to be determined in advance, while taking into account important and relevant aspects raised by the interviewee that could have been forgotten by the interviewer. The designers were asked questions that were intended to be open-ended, rather than being intended to guide the answers. These questions covered the profession of an instructional designer (specifically, the main steps involved in planning training), learning objects (LPOs), "good practices" and distance teaching. Interviews were carried out with nine pedagogical designers working at three different centres, and ranged from 30 to 60 minutes in length. These interviews were recorded, transcribed and coded so that each person's responses could be compared and the results analyzed. A number was assigned to each person interviewed in order to protect their anonymity. All respondents signed a consent form in which they agreed to participate in the research project by completing a questionnaire and answering interview questions.

These interviews confirmed the need to take into account certain variables when planning a training course and that reused materials must be adapted to the cultural particularities of the new clientele (iteration 1 question in table 1). They also confirmed that a method is needed for dealing with cultural variables in a way that would allow them to be addressed systematically.

A questionnaire about the educational design history of the designers was completed by the participants. It provided information about their professional experience and needs. This information complements or confirms the information gathered during the semi-structured interviews.

The analyses conducted during iteration 1 suggest that a "Cultural Diversity" knowledge base may be essential to assist instructional designers in considering cultural variables or adapting to the current context (open borders, accessibility of distance education, etc.) since, even if they are interculturally competent, the designers will still require knowledge about the culture to which they are adapting 
the instructional material. At the end of iteration 1, two questions emerged: how does culture influence learning and teaching, and how can the notion of culture and its functions be defined?

The work involving iteration 2 helped to find answers to these questions and to begin to focus on the development (step 2 DBR), testing and refinement (step 3 DBR) of solutions.

The culture model synthesizes the research conducted in order to explain the influence of culture on learning and to define the notion of culture. The conceptualization work began with analyzing a selection of definitions of culture. After an analysis of these definitions and the evolution of the concept of culture, an adapted definition was formulated. Modeling work on key concepts and processes of culture was then carried out, resulting in the culture model presented in Section 3. While building the model, we sought to define the key concepts in order to complete the conceptual level (Mizoguchi, 2003) which is a structured collection of terms. These definitions have been validated by a linguist.

This first stage of the conceptualization work was validated by two experts: the first in cognitive sciences, and the second in intercultural analysis, specializing in management in an intercultural context. For the same reasons as those mentioned earlier, a semi-structured interview was chosen. The experts were asked questions focusing on the clarity of the semi-formal model, its completeness and consistency with cognitive science literature and, finally, the relevance of the concepts used, the relationships between them and the definitions formulated. The document was modified based on the recommendations of the first expert before being submitted to the second expert for evaluation. The questions varied slightly from one expert to the other, depending on their respective fields of expertise.

The work done on iteration 2 suggested that a method for dealing with cultural variables that can be added to the instructional design process may be essential for designers who must take cultural variables into account. It was also apparent that a system to assist the instructional designer in the task of adapting the instructional design and using these tools ("Cultural Diversity" knowledge base, processing method) is necessary. However, to feed our ontologies and tools, the elements that vary from one culture to another within the pedagogical scenarios 
have to be defined. The following question guided the work of iteration 3: What varies in a pedagogical scenario from one culture to another?

Since the literature on the values that variables can have in different cultures is rather scarce, a Web-based questionnaire was designed to be completed by pedagogical designers working with different cultures. In order to ensure that the answers to this questionnaire allow for the instantiation of knowledge bases on different cultures, work on developing an ontology continued in parallel with work on the Web questionnaire. The two are therefore closely linked. We ensured that each of the questions asked was properly linked to an ontology concept and could eventually allow the instantiation of knowledge bases. The preparation of the questionnaire sometimes led us to review some of the ontology concepts, properties and links.

The Web questionnaire was chosen because it allows designers from different cultures to be reached without geographical and scheduling constraints. The designers approached could therefore complete the questionnaire whenever and from wherever they wanted. A certificate to this effect has been obtained from the TELUQ University Ethics Committee.

We have tried to limit the number of questions to reduce the time required to answer them and with the hope of obtaining a larger number of respondents. The average time taken by respondents was around twenty minutes.

In its final version, the questionnaire consists of four main sections. The first concerns the context in which instructional design is practiced. The following sections include a series of questions about local pedagogical practices. Questions on educational resources and on the various teaching and learning environments complete the questionnaire. The latter is attached as an appendix.

Instructional designers from various countries were asked to complete the questionnaire. Initially, a message was sent to instructional designers identified as being capable of providing local follow-up with their colleagues. These persons were situated in Mauritius, Morocco, Tunisia, Togo, Ghana, Antilles and Canada (French speakers), and were known by the author or had been referred by colleagues. A request was also sent to members of the BSQF (Belgium, Switzerland, Quebec, France), a professional community of active instructional 
designers working in higher education in these countries. In all, seventy respondents from eleven countries (on different continents) have begun the questionnaire. Fifty-five of them have completed it, giving us a completion rate of $78.6 \%$.

\subsection{Data Analysis}

The process of codification and qualitative analysis was mixed: deductive and inductive. On the one hand, it was deductive because we used answers to questions (which were, in fact, hypotheses about variables) to categorize the answers. On the other hand, it was inductive because new variables that emerge from the answers were identified, particularly from the open-ended questions. For the purposes of this research, only cultures for which a minimum of five respondents completed the questionnaire were considered. Thus, Quebec, Mauritius, France, Belgium and Gabon were selected.

The analysis work began with the compilation of the questionnaire responses. The purpose of this analysis was not to provide an exhaustive picture of the cultures represented or to assess the quality and accuracy of the responses, which would have required more extensive data collection. Rather, the purpose was to select information that could be used to identify concepts for the ontology and to instantiate the knowledge bases on cultural variables that would allow us to advise the instructional designer. It should be recalled here that this research is intended, first of all, to provide conceptual evidence about the importance of cultural variables in the practice of instructional design, and secondly, about the usefulness of cognitive informatics in assisting instructional designers who must take cultural variables into account. The study prepared using the data collected is in a sense a draft of a more complete and robust portrait of cultures that we still need.

Some of the steps that we could take in the future include, by way of example, a support system asking users to complete a questionnaire before using the support system, enabling us to continuously accumulate information about the cultures represented. A larger number of respondents would allow us to do a more detailed analysis of the variables in pedagogical design practices in national cultures. 


\section{3- The Conceptual Model of Culture (Iterations 1, 2)}

The notion of culture was first defined by Tylor (1871). Since then, culture has been defined in different ways and in different disciplines. For example, Kroeber and Kluckhohn (1952) produced an inventory of more than 200 definitions of the term 'culture' in English. Table 2 presents some of the elaborated definitions, including the one formulated by Kroeber and Kluckhohn.

Table 2 Selection of Definitions of the Notion of Culture

\begin{tabular}{|c|c|}
\hline Author & Definition \\
\hline Tylor E.(1871) & $\begin{array}{l}\text { "Culture... is that complex whole which includes knowledge, beliefs, } \\
\text { arts, morals, law, customs, and any other capabilities and habits } \\
\text { acquired by [a human] as a member of society." (as cited in Cuche, } \\
2004, \text { p. 16) }\end{array}$ \\
\hline $\begin{array}{l}\text { Kroeber A.L. and } \\
\text { Kluckhohn C. } \\
(1952)\end{array}$ & $\begin{array}{l}\text { "Culture consists of patterns, explicit and implicit, of and for behavior } \\
\text { acquired and transmitted by symbols, constituting the distinctive } \\
\text { achievements of human groups, including their embodiment in } \\
\text { artefacts; the essential core of culture consists of traditional (i.e. } \\
\text { historically derived and selected) ideas and especially their attached } \\
\text { values; culture systems may, on the one hand, be considered as } \\
\text { products of action, on the other, as conditional elements of future } \\
\text { action." (p. } 181 \text { as cited in Dahl, 2004, p. 2) }\end{array}$ \\
\hline $\begin{array}{l}\text { UNESCO } \\
(1982)\end{array}$ & $\begin{array}{l}\text { "Culture... is ... the whole complex of distinctive spiritual, material, } \\
\text { intellectual and emotional features that characterize a society or social } \\
\text { group. It includes not only arts and letters, but also modes of life, the } \\
\text { fundamental rights of the human being, value systems, traditions and } \\
\text { beliefs." }\end{array}$ \\
\hline $\begin{array}{l}\text { Hall E. and Hall M. } \\
\text { (1990) }\end{array}$ & $\begin{array}{l}\text { "Culture is a technical term used by anthropologists to refer to a system } \\
\text { for creating, sending, storing and processing information developed by } \\
\text { human beings, which differentiates them from other life forms. The } \\
\text { terms mores, tradition, custom and habit are subsumed under the } \\
\text { cultural umbrella. Sometimes culture is used in reference to the fine } \\
\text { arts. While art and literature do indeed form an important part of a } \\
\text { culture, in this book the term is used in its wider context." (p. 183) }\end{array}$ \\
\hline $\begin{array}{l}\text { Sperber D. } \\
(1996)\end{array}$ & $\begin{array}{l}\text { "Culture is the precipitate of cognition and communication in a human } \\
\text { population." }\end{array}$ \\
\hline $\begin{array}{l}\text { Bruner J. } \\
(2000)\end{array}$ & $\begin{array}{l}\text { "Culture is a symbolic phenomenon created by humans; it is a means of } \\
\text { legitimizing the 'reality' of certain products of the mind and of denying } \\
\text { this status to others. Culture acts in various manners. It provides us } \\
\text { with commonly shared categories that allow us to group together } \\
\text { events, objects, situations and crises... It gives shape to emotions, } \\
\text { hopes and expectations." (Free translation of p. 6, Culture et modes de } \\
\text { pensées) }\end{array}$ \\
\hline $\begin{array}{l}\text { Spencer-Oatey H. } \\
(2004)\end{array}$ & $\begin{array}{l}\text { "Culture is a fuzzy set of attitudes, beliefs, behavioral norms, and basic } \\
\text { assumptions and values that are shared by a group of people, and that } \\
\text { influence each member's behavior and his/her interpretations of the } \\
\text { "meaning" of other people's behavior." (p. 4) }\end{array}$ \\
\hline $\begin{array}{l}\text { Dahl S. } \\
(2004)\end{array}$ & $\begin{array}{l}\text { "... 'culture' consists of various factors that are shared by a given group, } \\
\text { and acts as an interpretive frame of behavior." }\end{array}$ \\
\hline
\end{tabular}


The existing definitions have been the subject of various criticisms (Alber, 2002). Many of the definitions did not represent the evolving nature of culture and its dynamic nature. Others were too evolutionist and did not allow cultures to be considered on an equal footing. In this case, the functions of culture are also important because they can help us understand how culture influences our lives, and more particularly learning and teaching.

An adapted definition was formulated, inspired by this selection of definitions, but principally by that of Spencer-Oatey (2004). We consider that this definition allows for an equitable comparison of cultures, and that it takes into consideration the evolutionary, dynamic nature of culture, and both the implicit and explicit components of culture. Culture is therefore considered as being:

an evolving (in both time and space) set of schemes that influences the behavior of each of the members of a given group, the manner in which the members of the group interpret the behavior of other persons and groups, and the processes of interpretation and representation that allow them to interact with their environment.

By schemes, we mean abstract mental representations that help to solve problems and guide actions while neglecting the details. These schemes are collectively formed and reproduced, but they are unevenly applied among the individuals who form the group. They often refer to tacit knowledge, which is unconscious. As illustrated in Figure 1, these schemes consist of interpretation schemes and manifestation schemes. Interpretation schemes are abstract mental representations of what is not directly observable and include, in particular, basic values and assumptions. Most of the time, they are tacit and embedded. They serve to evaluate and interpret the world (products and behaviors). Manifestation schemes are abstract mental representations of what we can normally observe and correspond to artifact schemes and behavior schemes. This definition serves as a basis for the conceptual model of culture that is presented in the following paragraphs. This conceptual model of culture represents the key concepts of culture, as well as the relationships that exist between these concepts. This model can be used both to understand how culture can affect learning and teaching and to compare and analyze different cultures. 


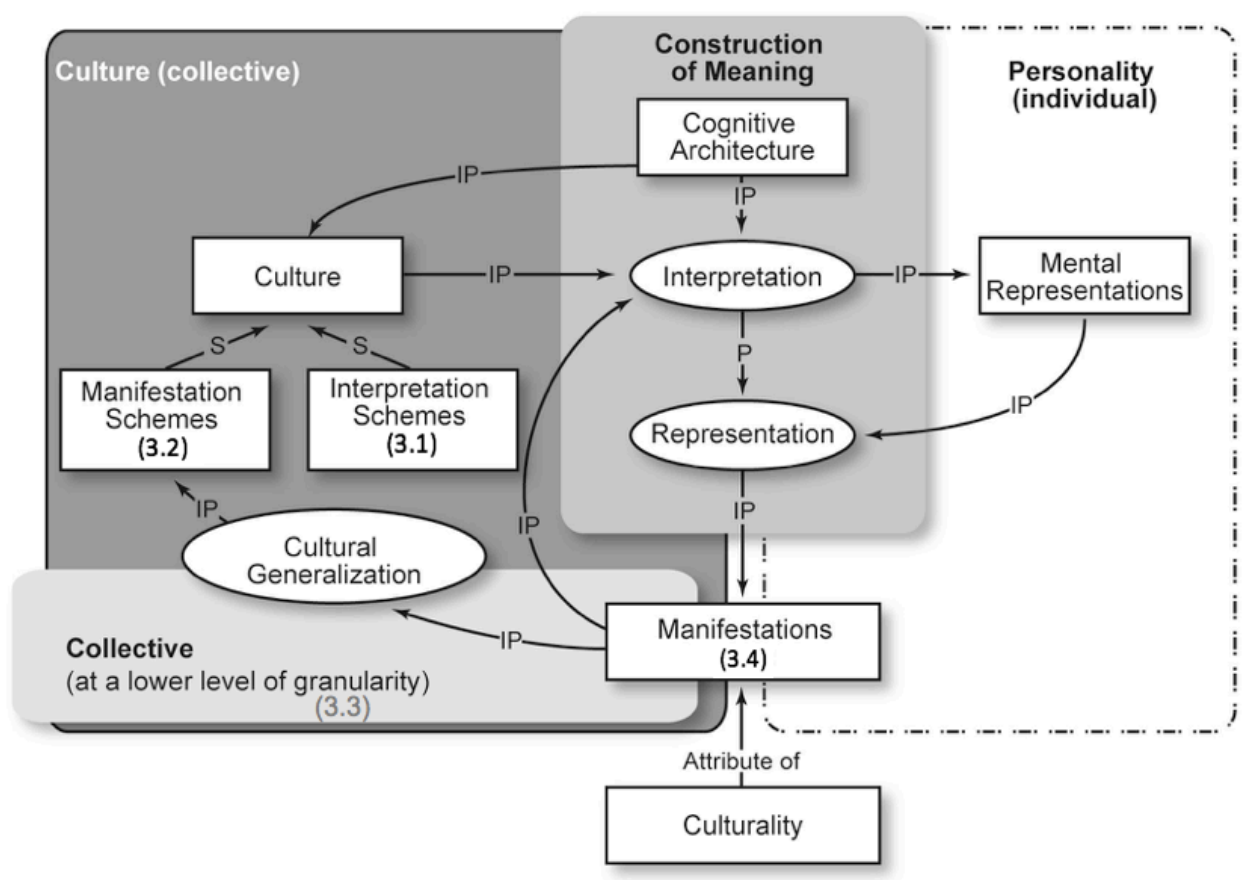

Figure 3 The Conceptual Model of Culture ${ }^{1}$

In Figure 3, culture (as a set of schemes) serves as an input to the process of interpretation, which allows us to build our mental representations of the world or of our environment (learning). These mental representations are then used as input to the representation process through which we represent the world (generally in order to share our mental representations or to interact with other individuals). The process of representation allows us to produce manifestations of culture. These may take the form of behavior or artifacts that we either keep for ourselves or share. They are not part of the culture at the granularity level considered, but they have the property of being tinted. We then speak about culturality (Abdallah-Pretceille, 1999), i.e., their association with cultural property. The concrete manifestations can then be reinterpreted and knowledge can be restructured and represented again, always under the influence of the schemes that make up the culture. Over time and after a number of iterations, the manifestations will disappear or move to a higher level via a "generalization process" and serve as schemes for the lower levels (and thus be part of the

\footnotetext{
${ }^{1}$ Figure 3 was designed using the knowledge editor software Mot+. The rectangles represent concepts and the ovals, processes. The " $i / p$ " links represent inputs or products, the " $p$ " links indicate precedence and the " $s$ " links may be read as "subset of".
} 
culture). The explanations for cultural evolution continue to multiply. Certain authors discussed memes (Dawkin, 1976; Dawkins, 1976; D. Dennett, 1991; D. C. Dennett, 2006), which are transmitted, similarly to genes, while others considered that culture changes only through learning and oppose nature and culture (Hofstede, 1984). In this conceptual model, cultural evolution is represented via the "Cultural Generalization" process.

According to Tooby and Cosmides (1992), all humans share a cognitive architecture that is universal and highly organized. This architecture consists of mechanisms that are rich in content and designed to meet the various "inputs" from local situations. This universal architecture is represented as an input to the process of interpretation. This interpretation process precedes the process of representation, since we cannot represent knowledge we do not possess. There is no representation without interpretation.

It is well known that the interpretation and representation processes are at the heart of all learning and teaching activities. When we learn, we interpret and we represent. When we teach, we interpret and we represent. Consciously or not (most often not), we use culture to interpret and to represent. This is how culture can influence teaching and learning.

Of course, different types of cultures exist, including organizational culture, national culture, professional culture, and adopted culture, to name a few. A single individual can share different cultures with different groups and individuals. Those that interest us in the context of this research are national cultures and the professional culture of instructional design. In the following subsections, we explain interpretation schemes, manifestations schemes, granularity levels and manifestations in greater detail. To facilitate the comprehension of Figure 3, we have added the numbers of the subsections under each concept represented and explained (see Figure 3).

\subsection{Interpretation Schemes}

Interpretation schemes are of primary importance because they affect all the products and processes considered in the procedural model. Most of the time, they are tacit and embedded. They are used, often unconsciously, to evaluate and interpret the world, and they may lead to emotions. 
Values, considered here as a type of interpretation scheme, are particularly important. For example, the approach towards time can lead to different interpretations (or misinterpretations) of a learner's or professor's behavior and could lead to negative emotions. The basic beliefs and assumptions, which may take the form of implicit conventions (e.g., what is right versus what is wrong), constitute other interpretation schemes, which are constituents of culture. Interpretation schemes contribute to the interpretation process, which in turn contributes to the mental representations that an individual constructs and uses for the representation process through which we produce different manifestations of culture (e.g., concrete artifacts). In Section 4, variables in interpretation schemes that can affect learning and teaching are presented.

\subsection{Manifestation Schemes}

Manifestation schemes may take the form of artifact schemes or behavior schemes.

Artifact schemes contain product schemes. In product schemes, a particular attention is paid to pedagogical scenario schemes. The pedagogical scenario is the product of the instructional designer's work and consists of a set of plans for the teaching and learning activities, the learning environment, the equipment and the educational resources that will be made available to learners, as well as the evaluation of the instruction. It can be for an activity, an entire course or even an entire curriculum. The scheme of a pedagogical scenario would therefore be the abstract mental representation (of what a pedagogical scenario should be or should contain) that an instructional designer would use to build a (concrete and sharable) pedagogical scenario (a manifestation/product, as defined below and represented in Figure 3).

Behavior schemes consist of attitudes, behaviors, both verbal and non-verbal, and rituals. Among the behavior schemes, there are those that pertain to the exercise of a profession. A profession that is of particular interest to us within the framework of this research is that of the instructional designer. Note that when he or she plans his or her course, the professor or the teacher plays the role of the instructional designer. In some cases, even the learner can be called upon to play the role of co-designer (Williams, Karousou, \& Mackness, 2011). 
The manifestation schemes contribute to the interpretation process, which in turn contributes to the mental representations that an individual constructs and uses for the representation process. They are not always explicit but are much more easily explained than the interpretation schemes because manifestations (which are observable) are directly related to them. In Section 4, variables in manifestation schemes that can affect learning and teaching are presented.

\subsection{Levels of Granularity}

A given culture is always shared by a group of individuals. Given the dynamic character of cultures, no key procedure allowing to identify the various cultures and to delineate them clearly in relation to each other was adopted, to our knowledge. However, in 1958, Lévi-Strauss proposed a solution still mentioned today. He speaks about "écarts significatifs" (significant distinctions) and says, "We call cultures any ethnographical group which, from the point of view of the investigation, presents, compared with others, some "écarts significatifs". [...] One collection of individuals, if objectively given in time and space, is simultaneously the result of several systems of culture: universal, continental, national, regional, local, etc." ([free translation] as cited in Alber (2002, p. 36).

Spencer-Oatey (2004) also pointed out that all members of a group are simultaneously members of different social groups. As examples, she cites groups formed by gender, ethnicities, occupations and generations. Various markers can then be used for the division allowing for the determination of the composition of the groups: geography, religion, leisure activities, the spoken language, professions, etc. For each of the divisions, we can also analyze the culture according to various levels of granularity: universal, continental, national, provincial, local, etc. As stated earlier, the same individual can belong to various cultural groups. Therefore, an instructional designer from Quebec belongs, among others, to the culture from Quebec and to the professional culture of instructional designers. He or she could have more in common with a Mauritian designer than with a plumber from Quebec.

A focus is made on the geographical features of cultures (at the national level), but based on a specific professional culture, that of instructional design, which 
targets learning. Figure 4 shows these levels of granularity and the area of interest.

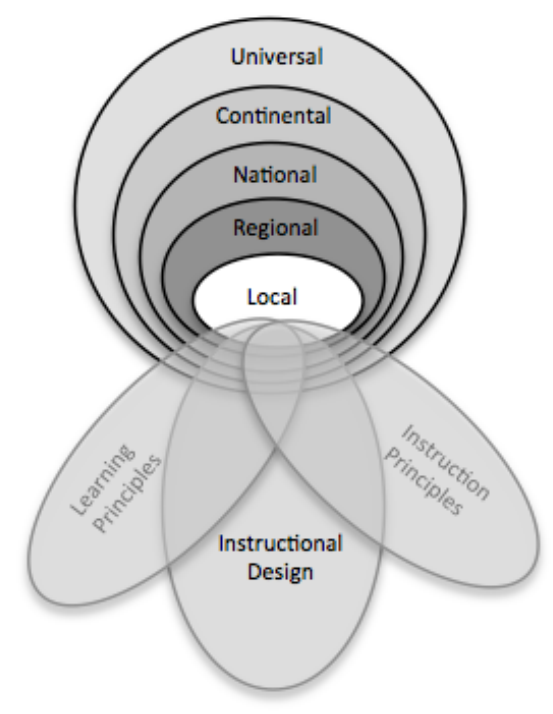

Figure 4 Granularity Levels and Cultures

One research question was: what could vary from one national culture to another within pedagogical scenarios. The research led to the identification of the cultural variables presented in Section 4.

\subsection{Manifestations}

Manifestations follow the same model as the manifestation schemes, i.e., they may take the form of artifacts or behaviors, with the exception that they are tied to the practice of culture and are observable and interpretable. They are located in time and space. The pedagogical scenario is considered here as a product, which is a manifestation of culture (of the instructional designers who belong to various cultural groups).

\section{4- Cultural Variables (Iterations 1, 2 and 3)}

The literature review and questionnaire response analysis allowed to target variables that have been grouped into three major categories, as shown in Figure 5: Values, Common Practices and Human Interactions.

The "Values" category was inspired by the work of Hall (1976), Hofstede (1984) and Parrish and VanBerschot (2010) and consists of the following variables: 
relationship with authority, tolerance for uncertainty, individualism/collectivism, approach towards time. As stated in the previous section, they are interpretation schemes. The other two categories (Common Practices and Human Interactions) are manifestation schemes and were inspired by the work of Reeves and Reeves (2008), McLoughlin (2007) and Powell (1997). The "Common Practices" category consists of the following variables: learning aims, lesson plan, rhythm of learning activities, learning situations, pedagogical communication, cooperation/collaboration, detailed feedback, summative evaluation methods, results interpretation. The "Human Interactions" category consists of the following: teacher's role, learner's role, reaching learning goals, available learning resources.

\begin{tabular}{|c|c|c|}
\hline \multicolumn{3}{|c|}{ Interoretation Schemes } \\
\hline Authoritarian & $\leftarrow$ Relationship with authority $\rightarrow$ & Egalitarian \\
\hline Low & $\leftarrow$ Tolerance for uncertainty $\rightarrow$ & High \\
\hline Individualism & $\leftarrow$ Individualism/Collectivism $\rightarrow$ & Collectivism \\
\hline Rigid & $\leftarrow$ Approach towards time $\rightarrow$ & Flexible \\
\hline \multicolumn{3}{|c|}{ Manifestation Schemes } \\
\hline \multicolumn{3}{|c|}{ Common Practices } \\
\hline Knowledge & $\leftarrow$ Learning aims $\rightarrow$ & Competencies \\
\hline Detailed - $A$ fixed contract & $\leftarrow$ Lesson plan $\rightarrow$ & Non-existent \\
\hline Big group & $\leftarrow$ Rhythm of learning activities $\rightarrow$ & Individual \\
\hline Academic & $\leftarrow$ Learning situations $\rightarrow$ & Authentic \\
\hline One-way & $\leftarrow$ Pedagogical communication $\rightarrow$ & Multi-way \\
\hline Absent & $\leftarrow$ Cooperation-Collaboration $\rightarrow$ & Omnipresent \\
\hline Absent & $\leftarrow$ Detailed feedback $\rightarrow$ & Continually provided \\
\hline Single (exam) & $\leftarrow$ Summative evaluation methods $\rightarrow$ & Several \\
\hline Normative & $\leftarrow$ Results interpretation $\rightarrow$ & Criterion-referenced \\
\hline \multicolumn{3}{|c|}{ Human Interactions } \\
\hline Transmitting knowledge & $\leftarrow$ Teacher's role $\rightarrow$ & $\begin{array}{r}\text { Guiding the learner, acting as } \\
\text { a mentor }\end{array}$ \\
\hline Remaining passive & $\leftarrow$ Learner's role $\rightarrow$ & $\begin{array}{r}\text { Constantly and actively } \\
\text { participating }\end{array}$ \\
\hline Teacher's responsibility & $\leftarrow \begin{array}{c}\text { Reaching learning goals } \rightarrow \\
\text { Shared responsibility }\end{array}$ & Learner's responsibility \\
\hline Teacher imposes a selection & $\begin{array}{c}\leftarrow \text { Available learning resources } \rightarrow \\
\text { Teacher proposes several, learner chooses }\end{array}$ & $\begin{array}{r}\text { Learner is expected to suggest } \\
\text { resources }\end{array}$ \\
\hline
\end{tabular}

Figure 5 Identified Cultural Variables

\subsection{Values}

The interpretation schemes are deeply embedded in individuals and are collectively shared. They can affect the behavior and the interpretation of the behavior of others in the various cultural groups to which the individual belongs (professional, sports, etc.). Here the works concentrate on the potential impacts on the professional culture of instructional design.

With the "Relationship to Authority" variable, the interest point was to know whether the relationship with the authority is hierarchical or egalitarian and to 
determine what impacts these interpretation schemes can have on manifestations (the course in the case that interests us).

In a hierarchical relationship, the professor is more authoritarian and tends to dictate what the students need to do. The latter avoid interrupting him or her during a presentation and follow the rhythm he or she imposes. In this type of relationship, a professor who does not know the answer to a question does not admit it to the students for fear of losing face. Furthermore, students will interact less with the professor and will avoid discussing what he or she says.

In an egalitarian relationship, the professor tends to consult the students and to consider their needs. The students put questions and engage in discussions when they feel the need to do so. They may discuss openly with the professor and disagree with his or her position, even in front of the group. The rhythm of the training can vary according to the needs expressed by the students or according to their interventions.

With the "Tolerance to Uncertainty" variable, the interest point was to verify whether tolerance to uncertainty was either high or low and to determine what impacts these interpretation schemes can have on manifestations (the course in the case that interests us).

In a culture where tolerance to uncertainty is low, the contents of the instruction are predetermined and very structured. The students expect a detailed lesson plan without ambiguity (similar to a contract). The professor most likely announces the details of the training well in advance and follows the plan (even if he or she gets better ideas as the course unfolds). The students want to know what the pedagogical goals are, as well as the methods and activities used to reach these goals. They expect specific evaluation criteria before the start of the course. They need to understand where the professor wishes to go with his or her pedagogical activities. In this context, the students do not tolerate last-minute changes well.

On the contrary, in a culture where tolerance to uncertainty is high, the students agree to learn as the course unfolds. There is greater room for the unexpected in these courses. Indeed, a course can take an entirely different direction than the 
one initially planned. The students can do activities suggested by the professor without knowing where it will take them.

With the "Individualism/Collectivism" variable, many aspects could be considered. In this case, the works concentrated on the "Competition/Collaboration" aspect. The idea was to verify whether the students valued competition more than collaboration among themselves. As pointed out by Rogers et al. (2007), we cannot manage teamwork in the same way in cultures where the students are very competitive and fight to obtain the best mark. We cannot always count on collaboration among students to reach educational goals, since the latter can benefit from the difficulties their colleagues experience.

On the other hand, in cultures where collaboration is valued, we can count on constructive exchanges between the students and plan educational activities in which their collaboration is requested and required. We can sometimes even count on the more talented students to help those experiencing difficulties.

With the "Approach toward Time" variable, the idea was to verify if the relationship with time was more or less flexible. In a culture where this relationship is less flexible, an instructional program must respect a predetermined and rigorous schedule. Assignments must be handed in to the professor on a predetermined date and late assignments are penalized. Adjustments to the calendar are not welcome.

On the other hand, in a culture where the relationship with time is more flexible, an instructional program can be adapted to the rhythm and needs of the learners. Courses can easily give way to the unexpected, and assignment due dates can be postponed to increase the quality of the learning and to adapt to the rhythm of the students.

\subsection{Common Practices}

With the "Learning Aim" variable, the goal was to verify what the habitual learning targets are: knowledge or competencies. It is well known that learning aims can vary according to the domain. Learning in some domains requires the acquisition of a significant amount of declarative knowledge, while other domains target procedural knowledge, and even the development of professional competencies. The view of knowledge can also vary according to the learning 
paradigm: it can be considered as a product or as a process. This is (almost) all independent of cultural variables and it is not a point of consideration here. Rather, the interest here lies in the fact that in some cultures, initial university training systematically targets knowledge. Competencies are developed after the entrance into professional practice. In other cultures, university training systematically targets the development of competencies. Training here seeks to equip students with a level of competency that allows them to be autonomous when they enter professional practice, and expertise is developed after the entrance into professional practice. When the learning aims are essentially knowledge to be transmitted, the roles of both the professor and the learner are impacted. The professor is often more a knowledge transmitter and the learner in such a context can be more passive. When knowledge is the target, learning activities can be developed in silos, i.e., in a stand-alone mode. The length of the training can generally be shorter. Conversely, when competencies are the target, the learner has to be more active and the professor often becomes a mentor or a guide in the apprenticeship of the learner. Competencies take longer to develop and require various learning activities. The learning activities cannot be developed in a stand-alone mode; they have to be complementary to each other. The professors involved in this type of program have to work as a team and plan together. Of course, a learning scenario that has competencies as a target is more complex to adapt than one that has knowledge as its target.

With the "Lesson Plan" variable, what interested us in particular was the importance given to the lesson plan or syllabus, and the level of detail of the latter. In some cultures, the lesson plan is a written document, similar to a contract, in which all the details for a course (and/or program) are explicitly stated. Professors tend to follow the plan, even if they get better ideas during the term. In other cultures, professors simply do not share lesson plans with the students. They have an idea of the content to be worked on, but they adapt the content (and the course) as they go along according to the needs and level of the learners. Sometimes, the learning targets can even differ from one learner to the next. A professor who is accustomed to presenting a detailed lesson plan before the 
beginning of the course can appear strange in a culture where learners do not even know what the function of such a lesson plan is.

With the "Rhythm of the Learning Activities" variable, the interest was in knowing whether the common practice was to impose a rhythm for the whole group, in which case it is the responsibility (or the problem) of the learner to adapt, or to plan according to different individual rhythms, where it is the responsibility of the professor to adapt.

With the "Learning Situations" variable, to know whether the common practice was to plan academic or authentic learning situations was the point of interest. According to Herrington, Oliver and Reeves (2003), authentic learning situations are directly related to the real world, i.e., they reproduce as faithfully as possible the tasks of professional practice instead of creating fictitious and "decontextualized" educational tasks. Academic situations are more artificial and are often created for the achievement of a learning objective that is not necessarily directly related to the real world.

With the "Pedagogical Communication" variable, the goal was to know whether communication was usually one-way (generally from the professor to the students) or multi-way (between the professor and the students and also between the students).

With the "Cooperation/Collaboration" variable, the research sought to determine whether the common practice was to plan many activities involving cooperation/collaboration or to avoid such activities completely, whether this variable is omnipresent or absent. These kinds of activities require learners to possess collaboration skills and cannot be effectively completed if learners do not have these skills (if they have never engaged in such activities, they probably do not have the skills).

With the "Detailed Feedback" variable, research wanted to know whether the common practice was to give formative feedback continually during a training program (or a learning activity), or if the practice was to give feedback and a mark (summative evaluation) only at the end. In some cultures, formative feedback is a requirement, and students can complain about a professor who does not give this kind of feedback. It can be difficult for a student who is used to receiving 
detailed feedback continually to adapt to a professor who gives marks only at the end. Likewise, it can also be difficult for a professor who is not used to giving detailed feedback to start giving it continually (if he or she teaches the course in another culture).

With the "Summative Evaluation Method" variable, the interest was in learning about evaluation practices; specifically, to find out whether several different evaluation methods were commonly used to evaluate the quality of student learning, or if only one method was used at the end. In some cultures, institutional rules impose the written exam as an evaluation tool for at least $80 \%$ of the final grade. It can be unsettling for a professor who normally does not use written exams but a variety of methods.

With the "Results Interpretation" variable, research wanted to know whether the common practice was to provide a normative or a criterion-referenced interpretation of the learning evaluation results. The normative interpretation is used to rank students against each other (often from the best to the worst), and it does not necessarily give information about the quality of the learning. The criterion-referenced interpretation refers to the quality of the learning by using pre-defined criteria. In cultures where normative interpretation is used, competition among students may be very high and it may be more difficult to get students to engage in collaboration activities.

\subsection{Human Interactions}

Formal human interactions involve roles and responsibilities on the part of each of the interacting individuals. Obviously, these roles and responsibilities create expectations among the interacting individuals.

With the "Teacher's Role" variable, the interest was in knowing whether the professor usually acts as a knowledge transmitter or as a guide/mentor. The usual roles create expectations among the actors, such as the expectations of the professor vis-à-vis the students and the students' expectations of the professor. Reeves (1997) addressed these issues and emphasized that what is at the core of educational practices in a given culture may be inappropriate in another culture. They gave the example of anticipating that students will question the knowledge 
presented in class and attempt to challenge the professor. This behavior on the part of students may be true in North America, but it is completely false in Europe.

The interest in the "Learner's Role" variable was similar to the previous variable. The goal was to know how students generally behave in class. Do they constantly and actively participate, or do they remain passive? If they actively participate, is it by working in class, putting questions, arguing and/or suggesting learning resources?

With the "Reaching Learning Goals" variable, the objective was to know whether it is the sole responsibility of the professor to reach the learning goals (if the learners fail to learn, it is their fault), whether the responsibility lies entirely with the learner or whether it is a shared responsibility. This can have a major impact on the course.

With the "Available Learning Resources" variable, the interest was to know whether it is normal to expect the students to suggest learning resources or not. In certain cultures, if the professor does not provide all the learning resources, he or she is not considered to be doing the job. In other cultures, however, it is considered an excellent pedagogical practice to ask students to select the learning resources that are more appropriate for their needs.

The work on the identification of variables allowed to develop a cultural variables ontology and a "Cultural Diversity" knowledge base, which brings together knowledge regarding five cultures: Québec, Mauritius, France, Belgium and Gabon. To populate the knowledge base, the cultures for which a minimum of five respondents had completed the questionnaire were used.

The ontology, the knowledge base and the prototype of the advisor system (which integrates the executable cultural adaptation method) were developed with the Tele-Learning Operating System (TELOS), presented by Magnan and Paquette (2008). 


\section{5- The Set of Tools Developed (Iterations 3, 4 and 5)}

On the basis of the identified variables presented in the previous section, the cultural variables ontology was engineered. Then, an executable cultural adaptation method ${ }^{2}$ for instructional designers who need to adapt their pedagogical scenario for learners with a different cultural background was developed. This method guides instructional designers in the fulfillment of adaptation tasks which allow them to produce an adapted pedagogical scenario. It brings together different software agents ${ }^{3}$ that provide adaptation advice to the user. These agents use the knowledge represented in the "Cultural Diversity" knowledge base, which is, as suggested by Mizoguchi (2004), built on the basis of the cultural variables ontology (which is built on the basis of the Conceptual Model of Culture presented in Section 3). Figure 6 illustrates these components and the relationships between them.

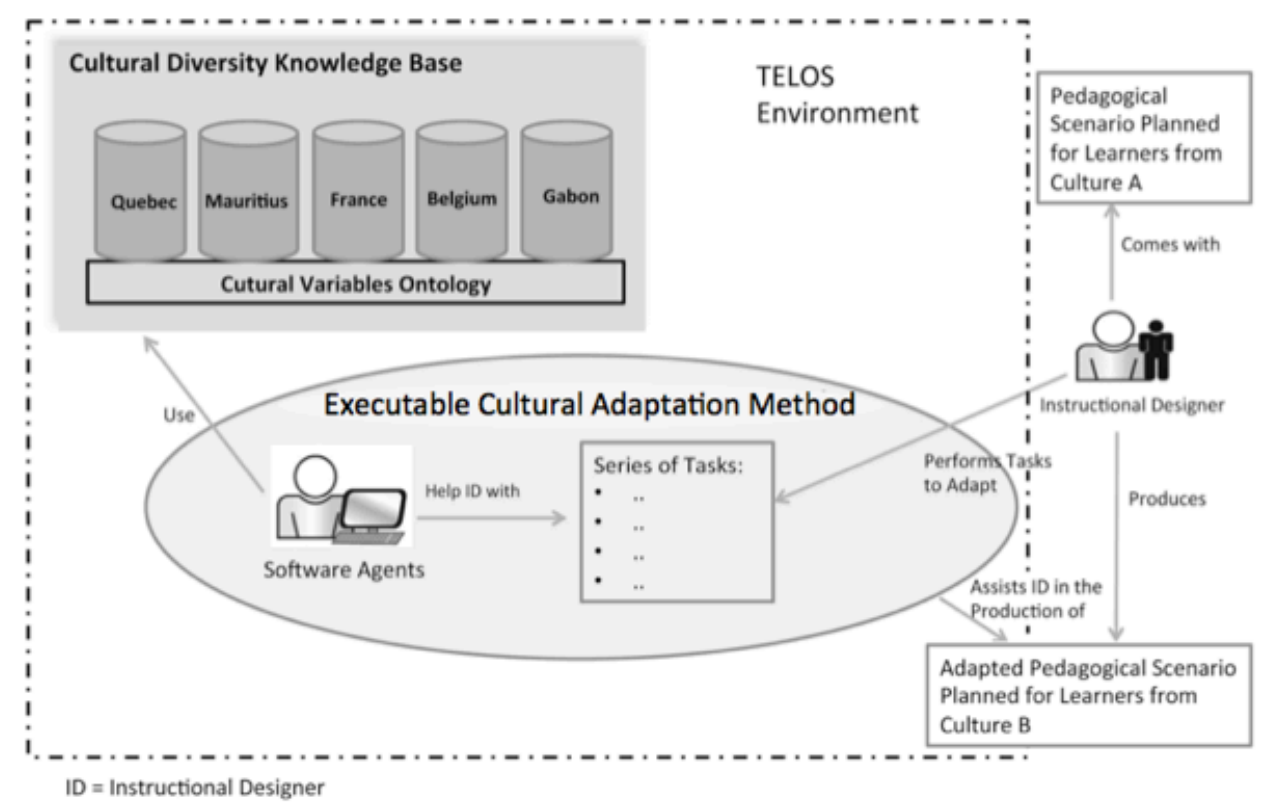

Figure 6 The Executable Cultural Adaptation Method and the "Cultural Diversity" Knowledge Base Used by the Advisor System in the TELOS Environment

\footnotetext{
${ }^{2}$ This part of the paper (presentation of the executable cultural adaptation method and advisor system) is derived from the CATS conference paper: Savard, I., Paquette, G., and Bourdeau, J. (2014).

${ }^{3}$ These software agents have their own responsibilities (e.g., to check the situation and give advice for one specific variable), but they are not aware of the responsibilities of other software agents in the system.
} 
In the following sections, each of these developments: the Cultural Variables Ontology, the "Cultural Diversity" knowledge base, the Cultural Adaptation method tasks and the software agents are described in greater detail.

\subsection{Cultural Variables Ontology and "Cultural Diversity" Knowledge Base}

The engineering work on the ontology alternated with the questionnaire design, the questionnaire response analysis and the variable identification. Following the identification and stabilization of the various concepts and of the relationships to establish between them, a more technical task that consisted in making the ontology computer interpretable by formalizing it was undertaken.

Figure 7 presents one part of the cultural variables ontology. An instance, represented by rectangles with trimmed corners in Figure 7, was created for each of the cultures represented within the framework of this research. Also evident in the diagram are the three major categories of variables presented in Section 4: Values, Common Practices and Human Interactions. Figure 7 clearly illustrates that values are considered as interpretation schemes and that common practices and human interactions are considered as manifestation schemes, as explained in Section 3.

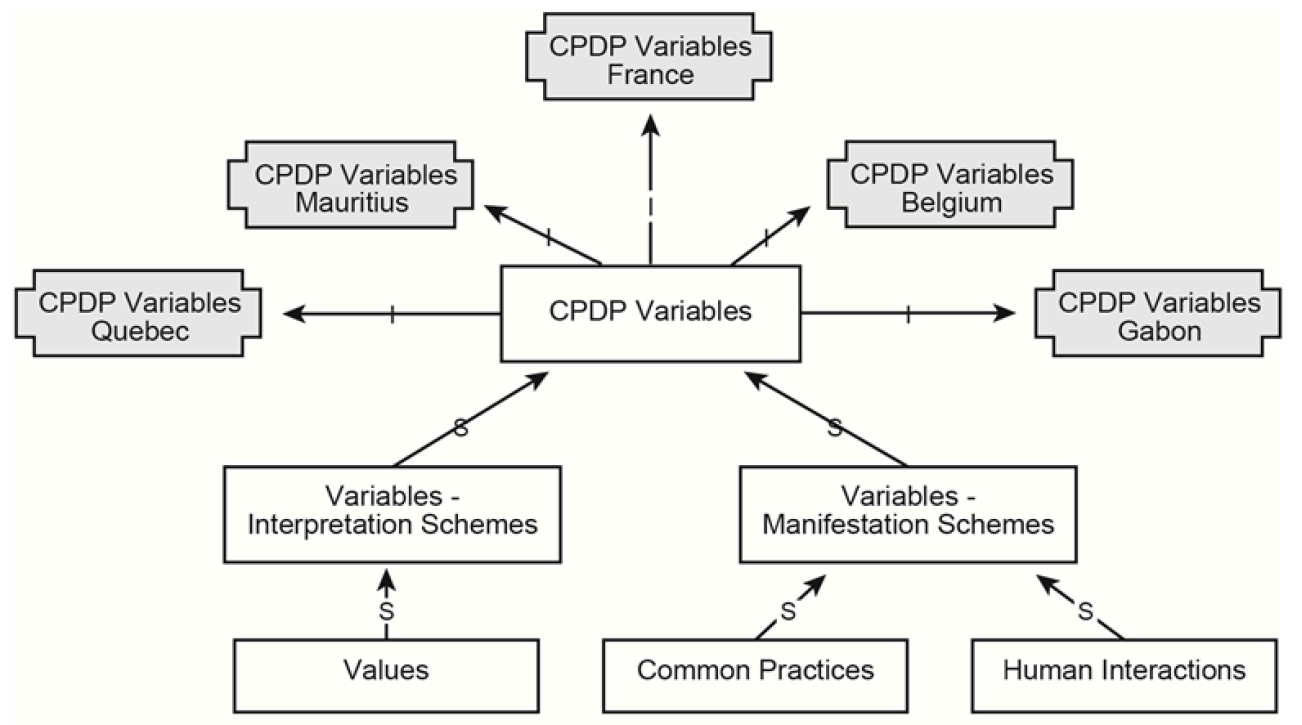

Figure 7 Cultural Variables in the Professional Culture of Instructional Design (CPDP in French) ${ }^{4}$

\footnotetext{
${ }^{4}$ Figure 7 was designed using the knowledge editor software Mot+. The rectangles represent classes. The "I" links represent instances and the " $\mathrm{S}$ " links may be read as "subset of".
} 
These three categories bring together all of the seventeen variables represented in the ontology and presented earlier in this article. As illustrated in Figure 6, the knowledge about each of the represented cultures is grouped together on the basis of this ontology. All of the knowledge represented in this manner constitutes the "Cultural Diversity" knowledge base.

For each of the cultural variables presented in Section 4 and on the basis of the responses obtained in the web-based questionnaire, the possible characterizations for each of the cultures represented were depicted. Then, were specified the particularities on the basis of the objects, attributes and characterizations of each of the cultural variables (CPDP Variables), which are concepts in the ontology. Figure 8 presents an example for the "Learner's Role" variable, which we have limited to a comparison between two cultures: Mauritius and France. Of course, all the data (for the five cultures) are represented in the actual knowledge base.

\begin{tabular}{|c|c|c|l|}
\hline \multicolumn{5}{|c|}{ VC-CPDP Ontology } \\
\hline \multicolumn{3}{|c|}{ Human Interactions (manifestation scheme) } \\
\hline Variable & Object & Attribute & \multicolumn{1}{|c|}{ Characterization } \\
\hline Learner's Role & & Has role & $\begin{array}{l}\text { Work in class } \\
\text { Ask questions } \\
\end{array}$ \\
& Mauritius Learner & & $\begin{array}{l}\text { Discuss } \\
\text { Suggest resources }\end{array}$ \\
& & & Listen passively \\
& & Hork in class \\
& Francele Learner & & Discuss \\
\hline
\end{tabular}

Figure 8 Example of an Object, Attribute and Characterization for the Cultural Variable "Learner's Role" in the "Cultural Diversity" Knowledge Base

The differences existing between the learners' roles in Mauritius and in France are shown in Figure 8. In Mauritius, learners habitually pose questions and suggest resources, which is not the case in France. Furthermore, in France, learners are more inclined to listen passively to their professor's lecture, unlike learners in Mauritius. Of course, this does not mean that all French students listen passively, 
and that all Mauritian students ask questions and suggest resources-it is only a portrait of usual practices. Knowing this, the French professor who gets ready to give his course in Mauritius will probably want to adapt his lecture or to go on with some verifications on his original pedagogical scenario. The following sections explain how the advisor system, with its software agents, can highlight these differences and advise the designer on possible adaptation strategies.

\subsection{The Cultural Adaptation Method}

As stated earlier, an executable cultural adaptation method in which the designer interacts with different specialized software agents was developed. When it finds a difference in the knowledge base, the specialized agent advises the designer about the different possibilities of adaptation.

This executable cultural adaptation method involves steps 2 to 5 in the method for cultural variable processing presented by Savard, Bourdeau and Paquette (2013), which consists of a total of seven steps:

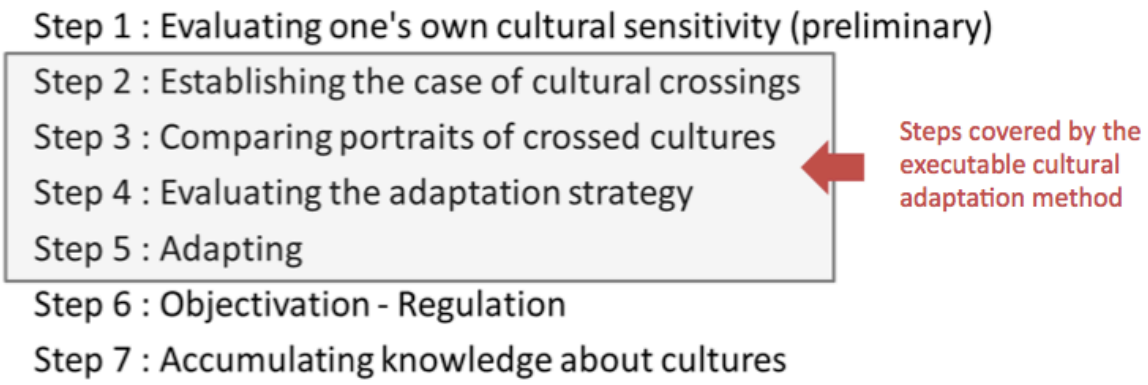

Figure 9 Steps in the Cultural Adaptation Method Covered by the Executable Version

Step 1 is considered as preliminary to the treatment of cultural variables and is completed for the time being with a questionnaire (external to the executable adaptation method) that was adapted from the work of Powell (1997). Steps 6 and 7 will be added to the system in a future version of the prototype that is planned to be used by instructional designers in authentic situations. For the time being, the method (steps 2 to 5 ) has been implanted in TELOS and has been tested on numerous occasions. It is therefore possible to confirm that it is functional, but it remains to be tested with a representative sample from the target clientele. 
Figure $10^{5}$ gives an overview of the formalized (executable) adaptation method. It begins with an analysis phase during which the designer goes through steps 2,3 and 4 of the method presented in Figure 9 and makes a decision about the reuse of the scenario (reuse as is, adapt or create a new one).

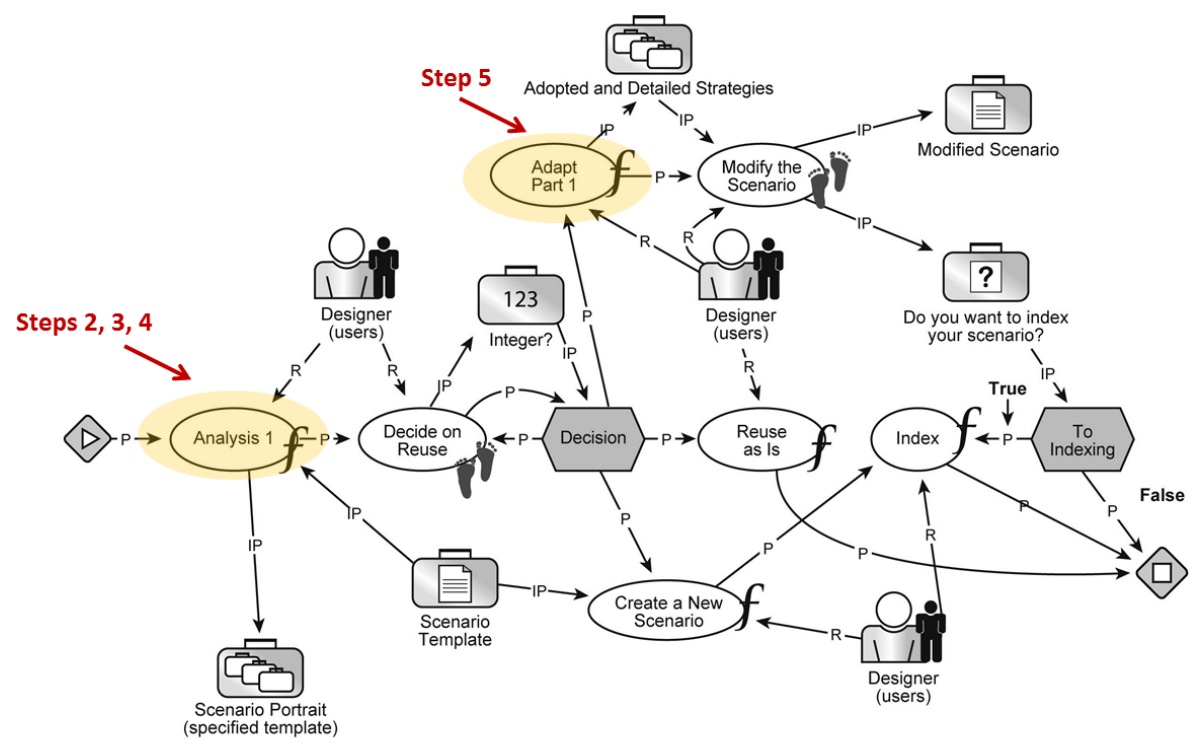

Figure 10 Overview of the Executable Cultural Adaptation Method

In the analysis phase, the instructional designer first informs the system about the case of cultural crossing by specifying his or her culture (or the culture of the learners for whom the scenario was first prepared) and the culture of the learners for whom he or she wants to adapt the scenario. The system takes this information and prepares the portraits of the two cultures by retrieving the information in the "Cultural Diversity" knowledge base. These portraits are in fact collections of characterizations that each of the variables takes. Each portrait groups together the triplets (object, attribute, characterization [ref. Figure 8])

\footnotetext{
${ }^{5}$ Figure 10 was designed using the TELOS scenario editor (Paquette, 2010).The suitcase with the document icon symbolizes a resource (here, the scenario template in PDF), the suitcase with the "123" icon symbolizes an integer (here, a number that represents the choice of answers offered: 1) reuse as is; 2) adapt; 3 ) create a new pedagogical scenario), the suitcase with many suitcases symbolizes a collection (here, the portrait of the scenario and the detailed and adopted strategies), and the suitcase with the question mark symbolizes a Boolean (here, the question, Do you want to index your scenario?). The intervener with the figure icon symbolizes a human intervener (here, the designer), and the oval shape symbolizes a process. A complex process involving sub-processes is marked with an $f$. An oval shape marked with small feet symbolizes an elementary human action. The hexagons symbolize decisions.
} 
specific to each of the five cultures under consideration. The designer then uses these portraits to answer the questionnaires (evaluation grid) that allow the system to evaluate the complexity level of adaptation. Figures 11 and 12 present the grids used in the advisor system.

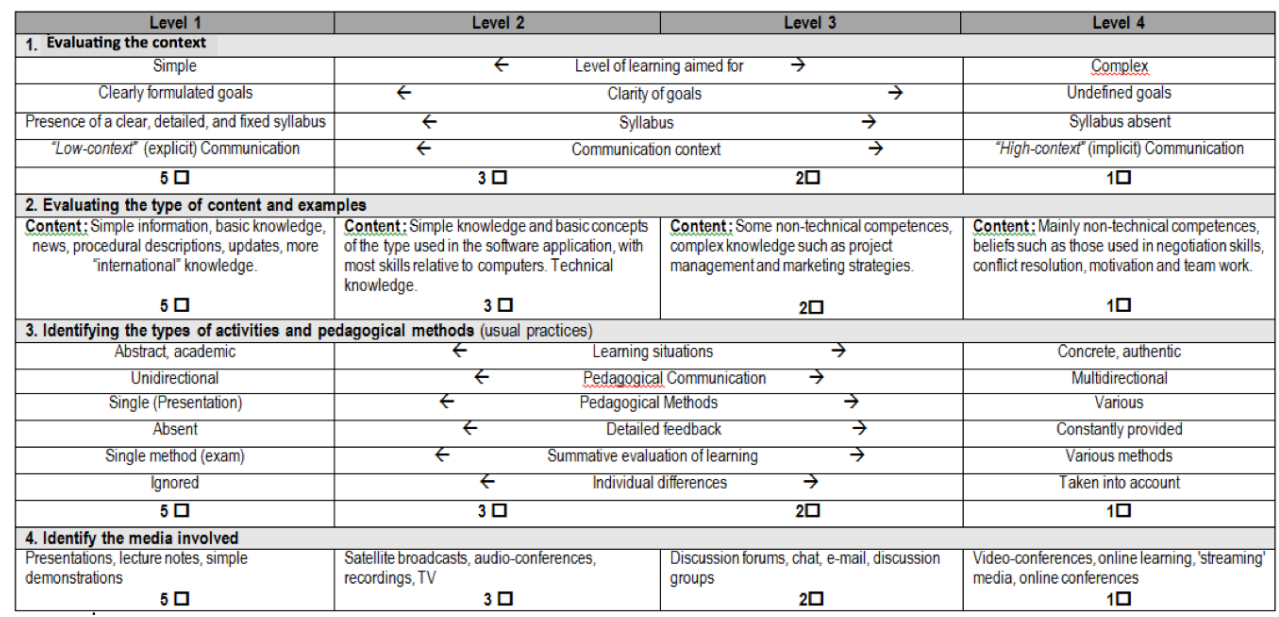

Figure 11 Evaluation Grid Completed by the Designer to Help the System Evaluate the Technical Adaptation Complexity (grid adapted from Edmundson (2007))

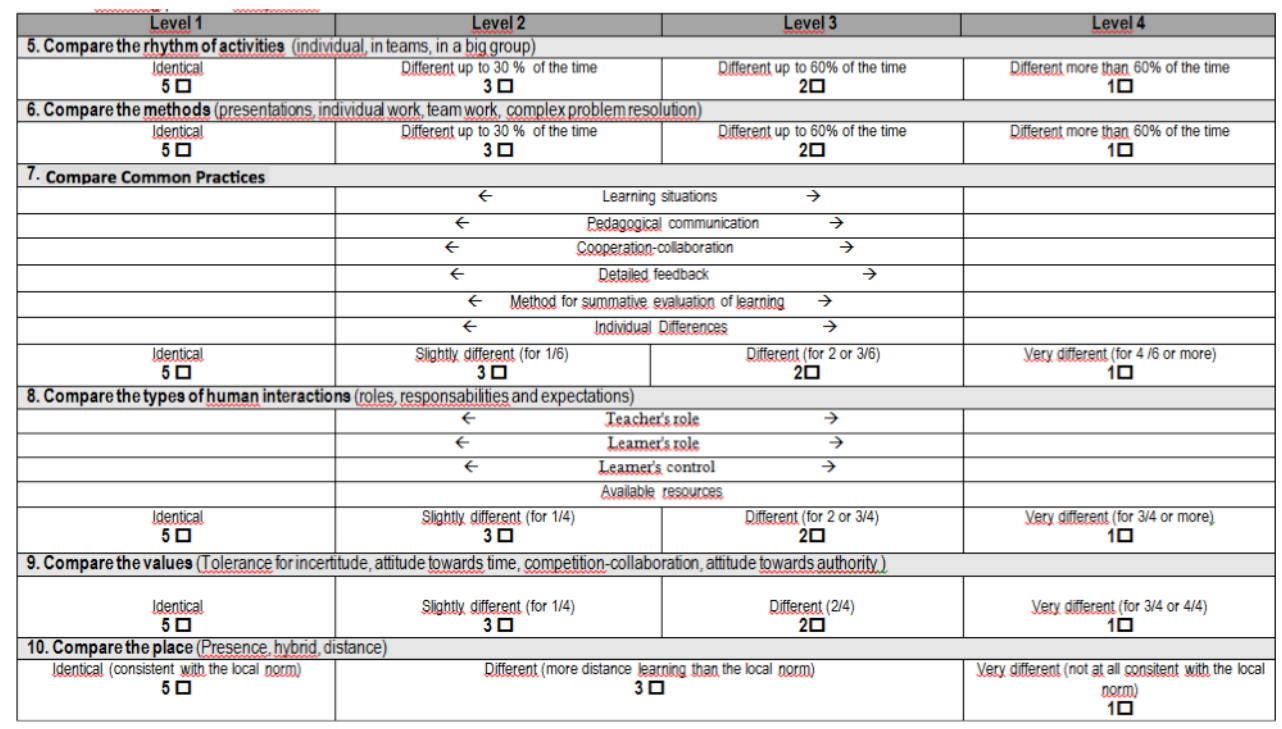

Figure 12 Evaluation Grid Completed by the Designer to Help the System Evaluate the Pedagogical Adaptation Complexity (grid adapted from Edmundson (2007))

By the end of the analysis phase, the designer receives advice about the technical and pedagogical adaptation complexity from the two software agents concerned. For each of the two evaluations, technical and pedagogical, one of the following global adaptation strategies (adapted from Edmundson (2007)) is suggested to the designer: translation/localization, contextualization, 
modularization or creation of a new scenario. The designer makes his or her decision on the basis of this advice and of the comparison of the portraits of the crossed cultures presented by the system. Reusing a scenario as is represents the simplest use case, since it leads the designer directly to the end of the adaptation process. Adaptation (Adapt) is the most complex case (Step 5 in the method presented in Figure 9). When it is too complex to adapt, it is sometimes better to create a new scenario. When major differences exist between the two cultures, the creation (Create) of a new scenario may also prove to be complex. If the designer wants to place the scenario in a repository, creation and adaptation both lead to indexation (Index), which is tied to the seventh and final step of the method: accumulating knowledge about cultures.

The comparisons (e.g., between the designer's culture and that of the learners whom he or she wishes to address) are all based on the concepts (identified cultural variables) of the ontology.

Figure 10 illustrates what we see as designers of the executable adaptation method, but Figure 13 presents the interface offered by TELOS (according to what has been designed in models like the one given in Figure 10) to the instructional designer or the professor (in the process of adapting a pedagogical scenario and who follows the designed executable cultural adaptation method).

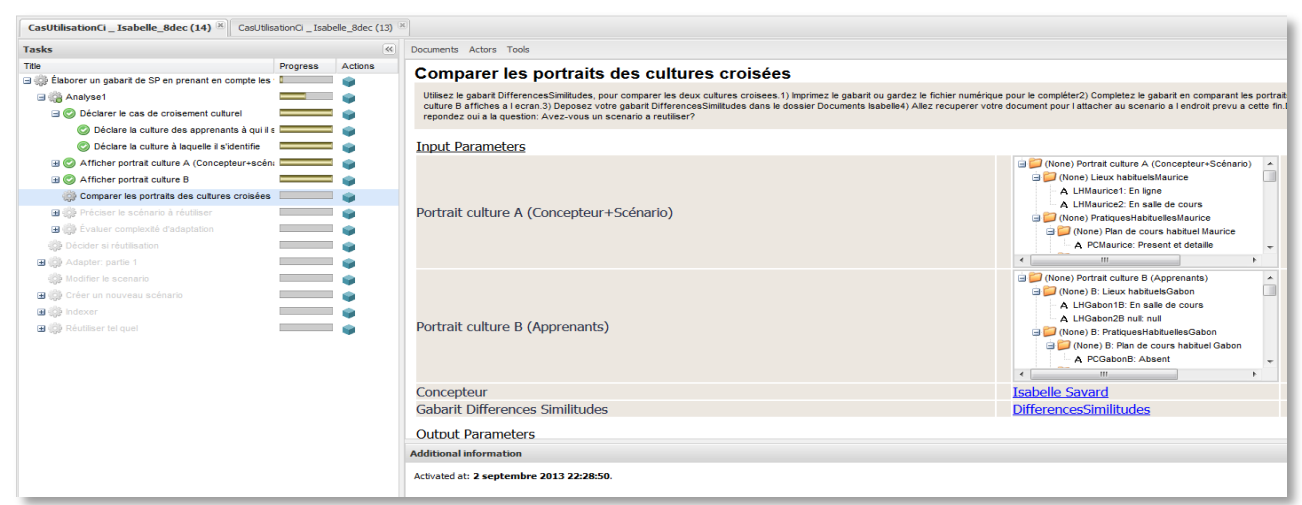

Figure 13 Interface of the Instructional Designer or the Professor (in the process of adapting a pedagogical scenario) in the Executable Cultural Adaptation Method in the TELOS Environment

On the left-hand side of the screen, the progress bars for each of the tasks that comprise the adaptation method are given. On the right, an example of a task in which the designer has to compare the portraits of the crossed cultures is 
given. To present the two portraits (Portrait A - designer's culture and Portrait B - learners' culture) and allow the designer to compare them, the system uses the knowledge from the "Cultural Diversity" knowledge base. This information makes it possible for the designer, in collaboration with designated software agents, to evaluate the adaptation (technical and pedagogical) complexity.

\subsection{The Software Agents}

As explained earlier, different software agents capable of advising the designers are placed in strategic locations in the digital adaptation method. Figure 14 illustrates one part of the cultural adaptation method in which the task "Develop the adaptation strategy for the summative evaluation methods" is accomplished in collaboration between the software agent (responsible for adapting the summative evaluation methods) and the designer. This gives an adaptation strategy as a product (represented by the "abc" suitcase) and marks the end of this part of the scenario.

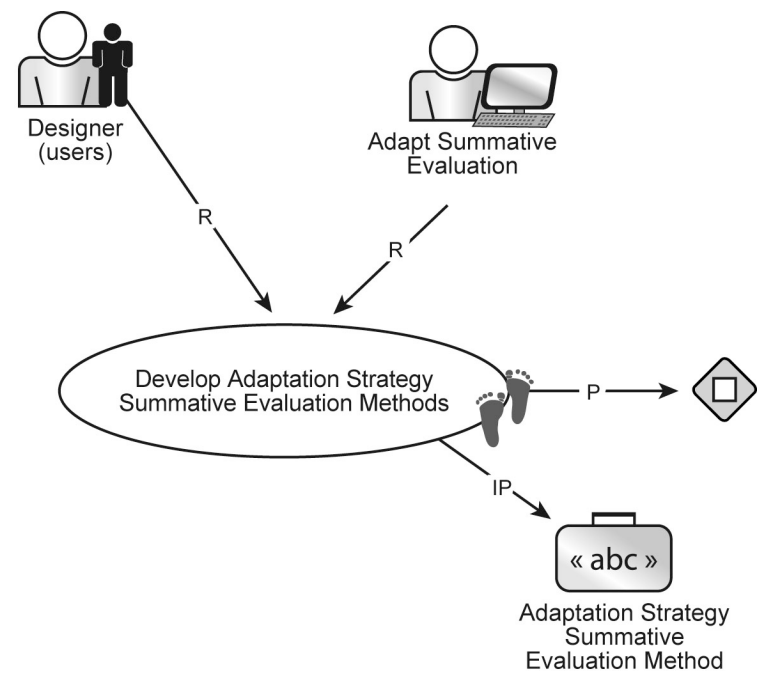

Figure 14 Collaboration between the Instructional Designer and the Software Agent Named "AdaptSummativeEvaluation"

If...Then rules are part of each of these software agents. An example of rules that concern the variable "Responsibility for Available Resources" is presented in Table 3 below. This variable ("Responsibility for Available Resources") concentrates on the fact that in some cultures, the responsibility for providing relevant resources (e.g., articles, videos, images, etc.) lies entirely with the professor, and the learners may be considered as relatively passive consumers, 
whereas in other cultures it is expected that learners will seek and suggest relevant resources (it may be part of the pedagogical scenario and be considered as an excellent pedagogical practice).

Table 3 Example of Rules in the Software Agents for the variable "Responsibility for Available Resources"

\begin{tabular}{|l|l|l|}
\hline \multicolumn{2}{|c|}{ Use Case: Adapt: Adapting Human Interactions } \\
\hline Software Agent: AdaptResponsibilities AvailableResources \\
\hline Name of the Rule & If... & \multicolumn{2}{|c|}{ Then display...: } \\
\hline $\begin{array}{l}\text { DecreaseResponsibiliti } \\
\text { esResourcesLearner }\end{array}$ & $\begin{array}{l}\text { ScenarioResponsibilitiesForRes } \\
\text { ources=-Learner must } \\
\text { contribute AND } \\
\text { Role1LearnerCultureB!=Sugges } \\
\text { t resources AND } \\
\text { Role2LearnerCultureB!=Sugges } \\
\text { t resources AND } \\
\text { Role3LearnerCultureB!=Sugges } \\
\text { t resources AND } \\
\text { Role4LearnerCultureB!=Sugges } \\
\text { tresources AND } \\
\text { Role5LearnerCultureB!=Sugges } \\
\text { t resources }\end{array}$ & $\begin{array}{l}\text { The learners whom you wish to address are not normally } \\
\text { required to suggest resources, so you propose a scenario } \\
\text { for which they are required to do so. } \\
\text { We advise you to make sure they know how and where to } \\
\text { look. If they do not, it is preferable to teach this first. } \\
\text { If you do not have time to teach the basics of research, } \\
\text { direct the students to resources that will assist them in } \\
\text { developing these skills (e.g., the library). } \\
\text { You can go slowly and ask for fewer resources in the } \\
\text { beginning and later increase the level of involvement on } \\
\text { the part of the students. } \\
\text { You can also begin by suggesting a variety of resources to } \\
\text { them and asking them to select the most useful ones for } \\
\text { them from your suggestions. }\end{array}$ \\
\hline
\end{tabular}

In all, there are nineteen software agents (seventeen variables and two for complexity adaptation evaluation) and a total of one hundred and twenty rules such as the one represented in the example. Further examples are presented in Table 4 below. 
Table 4 Further Examples of Rules in the Software Agents

Use Case: Adapt: Adapting the location

\begin{tabular}{|c|c|c|}
\hline \multicolumn{3}{|c|}{ Software Agent: Adaptlocation } \\
\hline Name of the Rule & If... & Then display...: \\
\hline UnknownLocation & & $\begin{array}{l}\text { The location that you have declared is not known to our } \\
\text { system. The known places are: In the classroom, Hybrid, } \\
\text { Online. }\end{array}$ \\
\hline LessDistance & $\begin{array}{l}\text { LocationCultureAScenario== } \\
\text { hybride } \\
\text { AND } \\
\text { LocationCultureBLearner==in } \\
\text { classroom } \\
\text { OR } \\
\text { LocationCultureAScenario== } \\
\text { On Line } \\
\text { AND } \\
\text { LocationCultureBLearner==in } \\
\text { classroom }\end{array}$ & $\begin{array}{l}\text { The learners you want to address are not used to online } \\
\text { training, or even hybrid training. } \\
\text { Before choosing this location, we advise you: } \\
\text { 1) to check whether the infrastructure is available on site } \\
\text { (access to computers, reliability of the Internet connection, } \\
\text { etc.); } \\
\text { 2) Ensure, if the infrastructure is available, that learners have } \\
\text { the necessary skills to complete online activities: } \\
\text { a) If the learners have the required skills, be sure to provide } \\
\text { clear instructions and provide complete and ongoing } \\
\text { support. We recommend that you check more regularly to } \\
\text { ensure that online activities are running smoothly; } \\
\text { b) if the learners do not have the required skills, plan training } \\
\text { or adapt activities to take place in the classroom. }\end{array}$ \\
\hline MoreDistance & $\begin{array}{l}\text { LocationCultureAScenario }==\mathrm{i} \\
\mathrm{n} \text { classroom } \\
\text { AND } \\
\text { LocationCultureBLearner }==0 \\
\mathrm{n} \text { Line }\end{array}$ & $\begin{array}{l}\text { The learners you want to address are used to taking their } \\
\text { courses online, and you are planning classroom training. } \\
\text { We advise you: } \\
\text { 1) to check if a room is available and if learners are able to go } \\
\text { there (they may be widely dispersed throughout the } \\
\text { territory); } \\
\text { 2) If a room is available and learners are able to go there, we } \\
\text { advise you to send a reminder the day before the training, } \\
\text { providing the room number. It would also be a good idea to } \\
\text { explain to learners why you think it is better to have them } \\
\text { travel for this training; } \\
\text { 3) if you cannot give the course in person, we advise you to } \\
\text { adapt your scenario so that it is available online. You can } \\
\text { contact the local technical support team. Someone will } \\
\text { probably be able to help you. }\end{array}$ \\
\hline
\end{tabular}




\begin{tabular}{|c|c|c|}
\hline \multicolumn{3}{|c|}{ Use Case: Adapt: Adapting practices } \\
\hline \multicolumn{3}{|c|}{ Software Agent: AdaptLessonPlan } \\
\hline Name of the Rule & If... & Then display...: \\
\hline AddLessonPlan & $\begin{array}{l}\text { LessonPlanScenario } A==\text { Abse } \\
\text { nt } \\
\text { AND } \\
\text { LessonPlanCultureB==Presen } \\
\mathrm{t}\end{array}$ & $\begin{array}{l}\text { ADAPT LESSON PLAN : } \\
\text { The learners you want to talk to are used to receiving a lesson } \\
\text { plan at the beginning of the course. We recommend that you } \\
\text { contact colleagues on site or the program director of the } \\
\text { program that is applicable to your course to find out what } \\
\text { should be included in the course outline. }\end{array}$ \\
\hline $\begin{array}{l}\text { AddDetailedLesson } \\
\text { Plan }\end{array}$ & $\begin{array}{l}\text { LessonPlanScenario } A==A b s e \\
\text { nt } \\
\text { AND } \\
\text { LessonPlanCultureB==Presen } \\
\text { t and Detailed }\end{array}$ & $\begin{array}{l}\text { ADAPT LESSON PLAN : } \\
\text { The learners you want to address are used to receiving a } \\
\text { detailed lesson plan at the beginning of the course. This } \\
\text { course outline generally includes details of the planned } \\
\text { teaching, learning and evaluation activities. It may also } \\
\text { include policy advice (e.g., policy on the use of the French } \\
\text { language, policy on late penalties, etc.). This lesson plan is } \\
\text { sometimes perceived as a contract between students and the } \\
\text { teacher. It can be a must in some cultures. } \\
\text { We recommend that you contact colleagues on site or the } \\
\text { program director of the program that is applicable to your } \\
\text { course to find out what should be included in the course } \\
\text { outline. }\end{array}$ \\
\hline PresentLessonPlan2 & $\begin{array}{l}\text { LessonPlanScenario==Presen } \\
\mathrm{t} \\
\text { AND } \\
\text { LessonPlanCultureB==Absent }\end{array}$ & $\begin{array}{l}\text { The learners you want to address are not used to receiving a } \\
\text { lesson plan. } \\
\text { We recommend that you take the time to present your lesson } \\
\text { plan and explain in detail what it means to you. If it is a } \\
\text { contract between you and the learners, this must be explicitly } \\
\text { stated. Be clear, especially about the delivery of work; if you } \\
\text { want the work to be delivered on a set date, you have to say } \\
\text { so. In some cultures, work is postponed until when it is } \\
\text { completed and there is no deadline to meet. }\end{array}$ \\
\hline \multicolumn{3}{|c|}{ Use Case: Adapt: Adapting practices } \\
\hline \multicolumn{3}{|c|}{ Software Agent: AdaptRhythmLearningActivities } \\
\hline Name of the Rule & If... & Then display...: \\
\hline AddActivities3 & $\begin{array}{l}\text { RhythmScenario==BigGroup } \\
\text { AND } \\
\text { Rhythm3CultureB==InTeam } \\
\text { OR } \\
\text { Rhythm3CultureB==Individu } \\
\text { al }\end{array}$ & $\begin{array}{l}\text { ADAPT RHYTHM : } \\
\text { The learners you want to address are used to working in } \\
\text { teams or individually to learn. They are not used to working } \\
\text { only in large groups and following the teacher's pace. We } \\
\text { recommend that you add a few activities where the learners } \\
\text { will work in teams or individually to break up periods when } \\
\text { they are more passive. }\end{array}$ \\
\hline AnnounceActivities & $\begin{array}{l}\text { RhythmScenario==Individual } \\
\text { OR } \\
\text { RhythmScenario==InTeam } \\
\text { AND } \\
\text { Rhythm1CultureB==BigGrou } \\
\text { p AND } \\
\text { Rhythm2CultureB==null } \\
\text { AND } \\
\text { Rhythm3CultureB==null }\end{array}$ & $\begin{array}{l}\text { ADAPT THE RHYTHM: } \\
\text { The learners you are talking to are not used to working during } \\
\text { classes. They are used to following and listening to the } \\
\text { teacher. We advise you to provide a detailed explanation to } \\
\text { the learners about team and individual activities, and about } \\
\text { the goals. We also advise you to give clear and detailed } \\
\text { instructions, since learners must learn how to do it in addition } \\
\text { to learning the content. }\end{array}$ \\
\hline
\end{tabular}

According to the rule or rules applied, based on the variables identified as requiring adaptation during the evaluation phase (Step 4 in Figure 9), various pieces of advice may be displayed for the instructional designer. He or she must 
then decide whether to accept the advice, reject it or adapt it. All the decisions that are taken are compiled by the system to form a collection: the detailed and adopted strategies (represented in Figure 10, at the top).

The designers may decide to adapt all the parts of their pedagogical scenario (identified as requiring adaptation) after completing their collection of detailed and adopted strategies, or they may do so as they detail and adopt each of the adaptation strategies.

Finally, as represented in Figure 10, the designers must decide whether or not to index their adapted pedagogical scenario on the basis of the new cultural parameters. We believe that indexing the scenarios on the basis of the cultural variables would facilitate the reuse of teaching and learning resources.

\section{6- Conclusion and Future Work}

The variable identification, including tools development, was completed over a period of eight years in the framework of a doctoral thesis (Savard, 2014) and is therefore the outcome of a long and thorough reflective process that is well anchored in the literature, our review of which served for both the questionnaire design and the final selection of the variables. The limited number of questionnaire respondents made it impossible for us to establish clear and reliable portraits of the five represented cultures, but the response analysis allowed to select certain variables and to leave others out. We believe we have successfully targeted some important variables that can have a real impact on the effectiveness of a pedagogical scenario and on the quality of learning. We plan to collect more data in order to extend the "Cultural Diversity Knowledge Base". In fact, we would like to establish clearer and more reliable portraits of the five represented cultures and to extend this part of the knowledge base (the "Francophonie Branch") by adding knowledge about new countries. Furthermore, one of the authors is planning to work on the "Asiatic Branch", which will contain knowledge about practices in Japan, China, Thailand and India. For now, the conceptual model is not directly usable by the system, but it has been used as a basis to develop an upper ontology of Culture (Savard \& Mizoguchi, 2016) which 
could be used as an instrument for cultural variables identification and data collection.

We believe that this modeling could prove to be very useful to the educational technology community and to designers who must adapt a pedagogical scenario to the needs of learners from another culture. It could, however, be improved, in particular by adapting it to make it usable by the learner as well, and by relating it to work such as that of Blanchard, Mizoguchi and Lajoie (2010), which dealt with a high-level ontology of culture, and that of Hayashi, Bourdeau and Mizoguchi (2008), which examined an ontology of teaching and learning theories. Indeed, it could be interesting to develop specialized agents with the task of evaluating the pedagogical coherence in the scenarios (according to the goal or the learning target and context). For example, an agent could intervene in a scenario where the learner is required to solve complex problems, but where the sole teaching method planned is the lecture.

This research allowed to develop tools that provide support to the designer in the difficult task that is cultural adaptation. To date, the method (steps 2 to 5 ) has been implanted in TELOS and has been tested on numerous occasions. It is therefore possible to confirm that it is functional, but testing remains to be done with a representative sample of the target clientele. A sixth iteration of DBR could be planned to allow us to focus on the implementation of the advisor system in authentic contexts and to put the emphasis on reflecting and refining it in collaboration with practitioners from different countries. This iteration should also be the opportunity for new tool developments in relation with steps 6 and 7 , which are the Reflective Sharing Process - Regulation (Step 6) and Accumulating Knowledge about Cultures (Step 7). As cultures evolve in time and space, we need methods that will allow us to collect and validate data on a regular basis and, if possible, automatically or semi-automatically.

Finally, this system prototype would work well on a small scale, with five represented cultures. It can assist the designers in their task of adapting to cultural variables. We believe, however, that it could become very difficult to use it with more than ten cultures. With a greater number of represented cultures, knowledge bases could be managed independently, outside the system. The 
designers could then create their own "world of action" by selecting the four or five cultures with which they plan to work and integrate them into their customized version of the advisor system.

It is also our intention to design an Intelligent Tutoring System (ITS) for cultural adaptation that could be integrated into basic instructional design training or proposed to learners who need to adapt. We consider that cultural adaptation is even more interesting if it has shared responsibilities between the learner and the teacher or the educational institution.

\section{Conflict of Interest:}

The authors declare that they have no conflict of interest.

\section{Acknowledgements}

Author A received an excellence award (scholarship) for her educational program from the Fonds de recherche du Québec - Société et culture - FQRSC (Government of Québec), from TÉLUQ and from the Doctorate in Cognitive Informatics program committee.

The first part of this research was made possible through funding received from the Canadian SSHRC Research Fund for the Learning Objects Repositories Network (LORNET) project. The authors would like to thank their colleagues, and particularly the development team of the LORNET project, for their valuable advice and comments. Special thanks to Michel Léonard, Alexis Miara, Mohamed Ben Jemia, Perry Lake and Karen Lundgren Cayroll.

The authors would like to thank Professor Riichiro Mizoguchi from the Japan Advanced Institute of Science and Technology (JAIST) for his advice and comments on an earlier version of this article.

The authors would like to thank Mary Eady for linguistic revision. 


\section{References}

Abdallah-Pretceille, M. (1999). L'éducation interculturelle (Vol. 3487). Presses Universitaires de France-PUF.

Alber, J. L. (2002). Le concept anthropologique de" culture": Repères et mises au point. Terra Cognita: Quelle Culture? Revue Suisse de l'intégration et de La Migration. Commission Fédérale Des Étrangers, 1, 34-40.

Bell, P. (2004). On the theoretical breadth of design-based research in education. Educational Psychologist, 39(4), 243-253.

Blanchard, E. G., \& Mizoguchi, R. (2014). Designing culturally-aware tutoring systems with MAUOC, the more advanced upper ontology of culture. Research \& Practice in Technology Enhanced Learning, 9(1).

Blanchard, E. G., Mizoguchi, R., \& Lajoie, S. P. (2010). Structuring the cultural domain with an upper ontology of culture. In The Handbook of Research on Culturally-Aware Information Technology: Perspectives and Models (pp. 179-212).

Brown, A. L. (1992). Design experiments: Theoretical and methodological challenges in creating complex interventions in classroom settings. The Journal of the Learning Sciences, 2(2), 141-178.

Bruner, J. S., \& Bonin, Y. (2000). Culture et modes de pensée: L'esprit humain dans ses oeuvres. Retz.

Collective, D.B.R. (2003). Design-based research: An emerging paradigm for educational inquiry. Educational Researcher, 32(1), 5-8.

Collins, A. (1992). Toward a design science of education. In New directions in educational technology (pp. 15-22). Springer.

Dahl, S. (2004). Intercultural research: The current state of knowledge.

Dawkin, R. (1976). The selfish gene. Oxford University Press, 1, 976.

Dawkins, R. (1976). 1989. The selfish gene. New edition. New York: Oxford University Press.

Dennett, D. (1991). Consciousness explained (london: Allen lane, 1992). Darwin's Dangerous Idea: Evolutions and Meanings of Life.

Dennett, D. C. (2006). Breaking the spell: Religion as a natural phenomenon (Vol. 14). Penguin.

DiSessa, A. A., \& Cobb, P. (2004). Ontological innovation and the role of theory in design experiments. The Journal of the Learning Sciences, 13(1), 77-103.

Edmundson, A. (2007). The Cultural Adaptation Process (CAP) Model: Designing E-Learning for Another Culture. In Globalized E-Learning Cultural Challenges (pp. 267-290).

Goodear, L. (2001). Cultural diversity and flexible learning.

Hall, E. (1976). 1981. Beyond culture. New York, NY: Doubleday/Anchor Books. 
Hall, E. T., \& Hall, M. R. (1990). Understanding cultural differences: [keys to success in West Germany, France, and the United States]. Intercultural Press.

Hayashi, Y., Bourdeau, J., \& Mizoguchi, R. (2008). Structurization of learning/instructional design knowledge for theory-aware authoring systems. International Conference on Intelligent Tutoring Systems, 573-582. Springer.

Herrington, J., McKenney, S., Reeves, T., \& Oliver, R. (2007). Design-based research and doctoral students: Guidelines for preparing a dissertation proposal. EdMedia: World Conference on Educational Media and Technology, 4089-4097. Association for the Advancement of Computing in Education (AACE).

Herrington, J., Oliver, R., \& Reeves, T. C. (2003). Patterns of engagement in authentic online learning environments. Australasian Journal of Educational Technology, 19(1).

Hofstede, G. (1984). Culture's consequences: International differences in work-related values (Vol. 5). sage.

Kember, D., Ma, R., \& McNaught, C. (2006). Excellent university teaching. Chinese University Press.

Kroeber, A. L., \& Kluckhohn, C. (1952). Culture: A critical review of concepts and definitions. Papers. Peabody Museum of Archaeology \& Ethnology, Harvard University.

Larman, C. (2004). Agile and iterative development: A manager's guide. Addison-Wesley Professional.

Man, S. (2004). Are preservice instructional designers adequately prepared for tomorrow's diverse learning audiences?: A cultural content analysis of textbooks (1993-2003) used for instructional design.

McLoughlin, C. (2007). Adapting e-learning across cultural boundaries: A framework for quality learning, pedagogy, and interaction. In Globalized e-learning cultural challenges (pp. 223-238). IGI Global.

Mizoguchi, R. (2004). Le rôle de l'ingénierie ontologique dans le domaine des EIAH. Entretien réalisé par Jacqueline Bourdeau. Ontologies Pour Les EIAH [Numéro Spécial]. Sciences et Technologies de l'information et de La Communication Pour l'éducation et La Formation, 11.

Mizoguchi, R. (2003). Part 1: Introduction to ontological engineering. New Generation Computing, 21(4), 365-384.

Mor, Y. (2011). Embedding design patterns in a methodology for a design science of e-Learning. In Investigations of E-Learning Patterns: Context Factors, Problems and Solutions (pp. 107-134). IGI Global.

Paquette, G. (2010). An ontology-driven System for e-learning and knowledge Management. In Visual Knowledge Modeling for Semantic Web Technologies: Models and Ontologies (pp. 302-324). IGI Global.

Paquette, G., \& Magnan, F. (2008). An executable model for virtual campus environments. In Handbook on Information Technologies for Education and Training (pp. 363-403). Springer. 
Parrish, P., \& Linder-VanBerschot, J. (2010). Cultural dimensions of learning: Addressing the challenges of multicultural instruction. The International Review of Research in Open and Distributed Learning, 11(2), 1-19.

Powell, G. C. (1997). On being a culturally sensitive instructional designer and educator. Educational Technology, 37(2), 6-14.

Reeves, P. M., \& Reeves, T. C. (2008). Design considerations for online learning in health and social work education. Learning in Health and Social Care, 7(1), 46-58.

Reeves, T. (2006). Design research from a technology perspective. In Educational design research (pp. 64-78). London: Routledge.

Reeves, T. C. (1997). A model of the effective dimensions of interactive learning on the World Wide Web. The University of Georgia.

Reeves, T. C. (2000). Enhancing the worth of instructional technology research through "design experiments" and other development research strategies. International Perspectives on Instructional Technology Research for the 21st Century, 27, 1-15.

Rogers, P. C., Graham, C. R., \& Mayes, C. T. (2007). Cultural competence and instructional design: Exploration research into the delivery of online instruction cross-culturally. Educational Technology Research and Development, 55(2), 197-217.

Savard, I. (2014). Modélisation des connaissances pour un design pédagogique intégrant les variables culturelles. Télé-université.

Savard, I., Bourdeau, J., \& Paquette, G. (2013). An Ontology and a Method to Support Instructional Design Integrating Cultural Variables. Proceedings of Culturally-Aware Technology-Enhanced Learning (CUITEL).

Savard, I., \& Mizoguchi, R. (2016). Ontology of Culture: A Procedural Approach for Cultural Adaptation in ITSs.

Savard, I., Paquette, G., \& Bourdeau, J. (2014). An advisor system for cultural adaptation in instructional design. Proceedings of the Fifth International Workshop on CulturallyAware Tutoring Systems (CATS2014).

Spencer-Oatey, H. (2004). Culturally speaking: Managing rapport through talk across cultures. A\&C Black.

Sperber, D. (1996). Explaining culture: A naturalistic approach. Cambridge, MA: Cambridge.

Tooby, J., \& Cosmides, L. (1992). The psychological foundations of culture. The Adapted Mind: Evolutionary Psychology and the Generation of Culture, 19.

Tylor, E. B. (1871). Primitive culture: Researches into the development of mythology, philosophy, religion, art, and custom (Vol. 2). J. Murray.

Unesco. (1982). Mexico City declaration on cultural policies. World Conference on Cultural Policies.

Wang, F., \& Hannafin, M. J. (2005). Design-based research and technology-enhanced learning environments. Educational Technology Research and Development, 53(4), 5-23. 
Williams, R., Karousou, R., \& Mackness, J. (2011). Emergent learning and learning ecologies in Web 2.0. The International Review of Research in Open and Distributed Learning, 12(3), 39-59.

Young, P. A. (2008). The culture based model: Constructing a model of culture. Journal of Educational Technology \& Society, 11(2), 107. 